بعض أنواع الذكاءات المتعددة كمؤشر تنبوئي لتعلم مهارتي التمريرة الصدرية والمحاورة

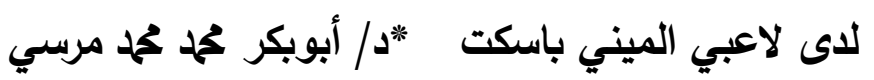

المقدمة ومشكلة البحث :

يثير العديد من التربويين إلي أن عملية التعلم تحدث نتيجة التفاعل بين بيئة التعلم بما تتضمنه من

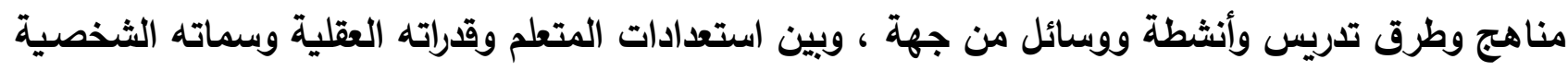

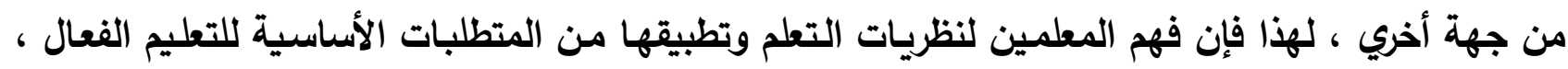
فهي تعطي مؤشرا عن كيفية حدوث التعلم ، ومن ثم فإنها تساعد المعلم علي إختيار الأساليب والأستراتيجيات

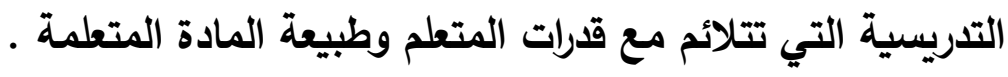

وتعتبر تنمية العقول البشرية أحدي المهام الأساسية في التربية لذا يجب علي القائمين بالعملية التعليمية الأخذ بالنظريات التعليمية التي تكثف أسرار العقل وكيفية حدوث التعلم والفهم والأخذ بأفكارها

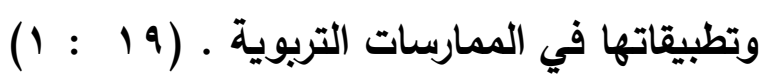

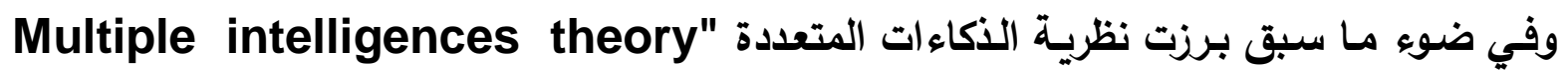

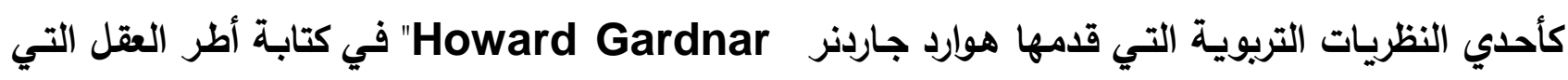
أحدثت منذ ظهورها ثورة في مجال الممارسـات التربوية والتعليمية فقد غيرت نظرة المعلمين عن تلاميذهم

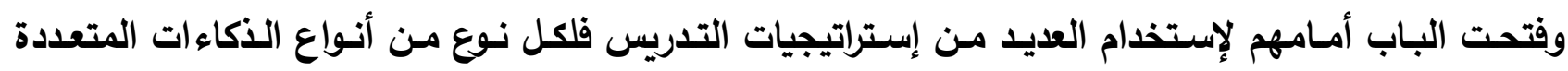

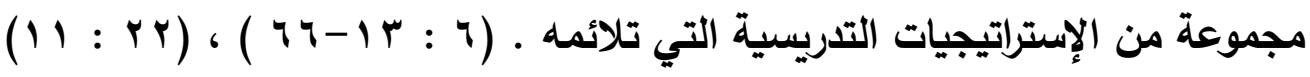
وأسساس هذه النظريـة أن الإنسـان يمتلك كحد أدنس سبعة أنواع من الذكاءات ولكن بنسب متفاوتة

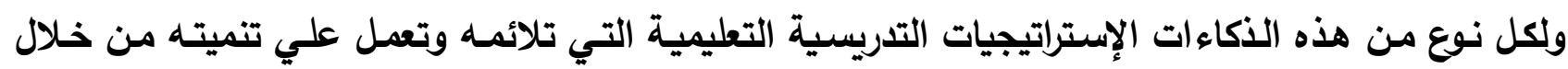

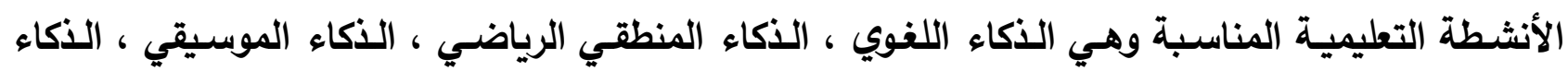

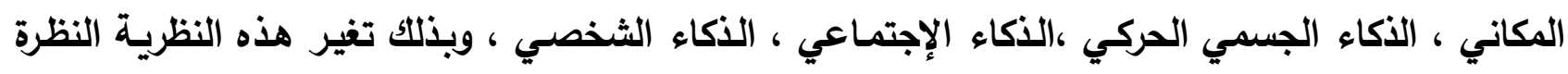

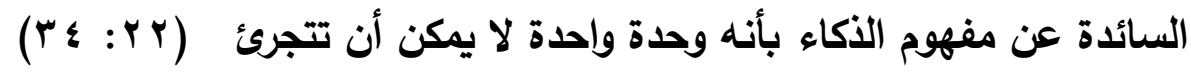

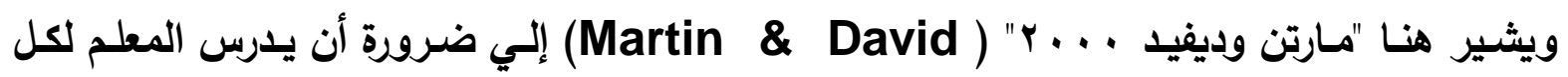

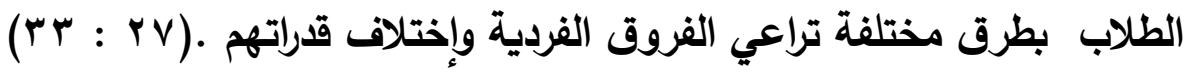

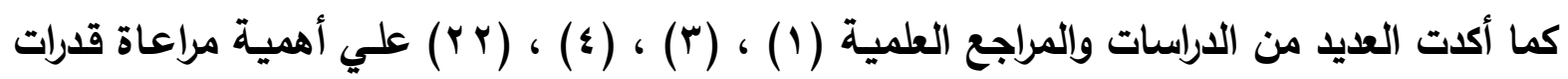

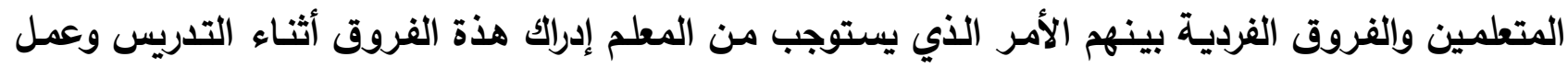

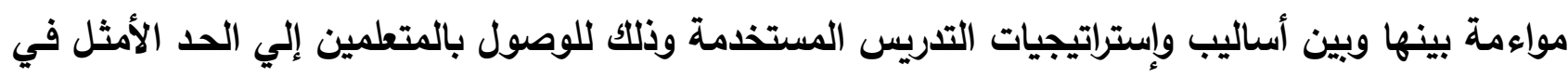

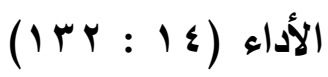


وقد جاءت نظرية الذكاءات المتعددة لتقدم المعرفة العمية من خلال الإنتقال من ذكاء إلي أخر ليتم

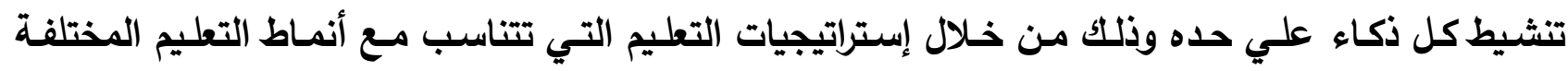

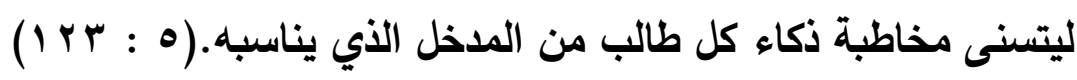

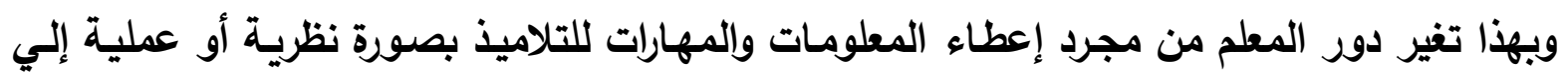

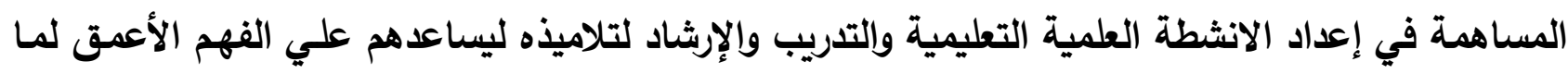

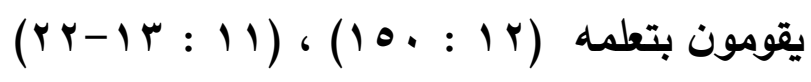
وتثير الأدبيات التربوية إلي أن نظرية الذكاءات المتعددة تقد إطاراً للمعلم للتعرف علي قدرة كل متعلم

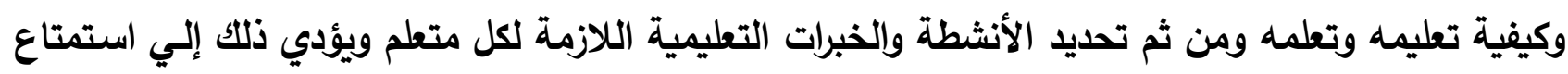

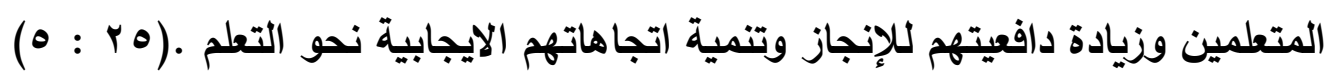

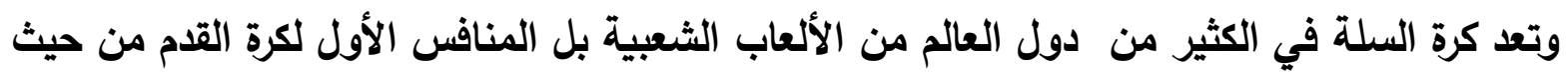

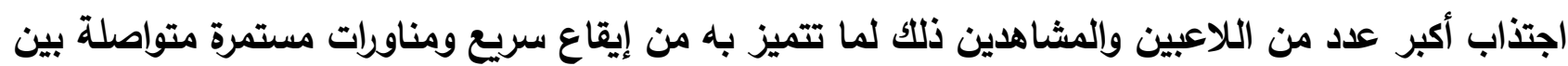
الهجوم والدفاع طوال المباراة .

ويرتبط الوصول للمستويات العالية في كرة السلة بمدي قدرات المدرب الرياضي علي إدارة عملية

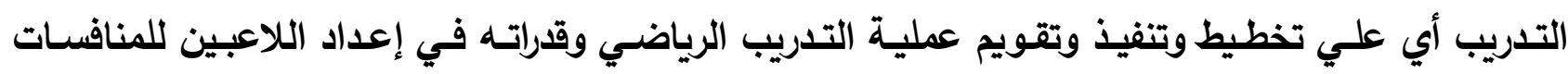

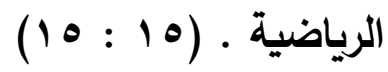
وتعتبر مرحلة الميني باسكت ( من · 1 إلي ب r سنة ) هي البداية الحقيقة لتعلم مهارات كرة السلة والتي تتؤثر تأثيراً بالغاً في المستوي الفني الذي يصل إليه اللاعب مستقبلاً خلال المراحل التنافسية التالية

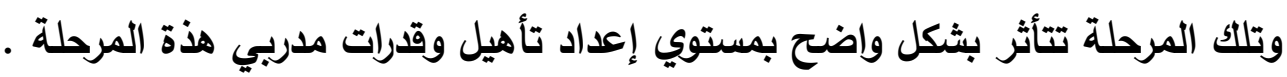

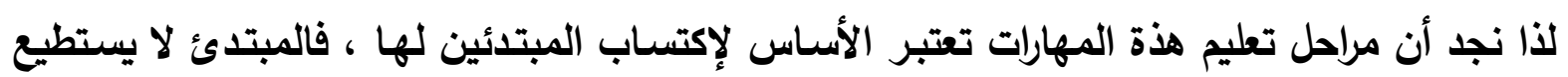

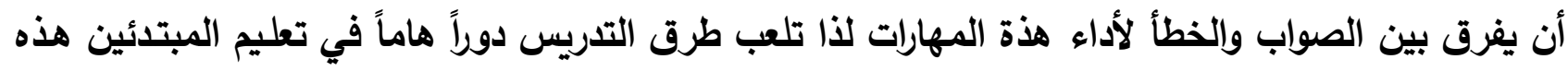

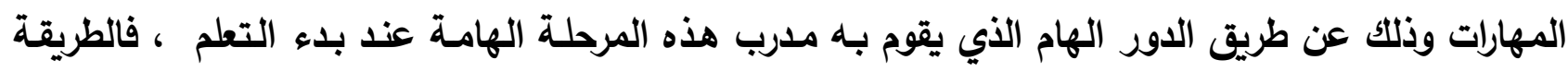

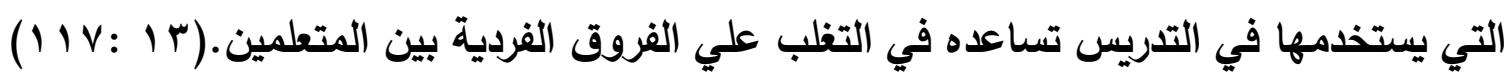
ويثير "عادل حسني السيد ، ووليد إبراهيم 9 . . ب" إلي أن التدريس الجيا يكسب المتعلم المعلومـات

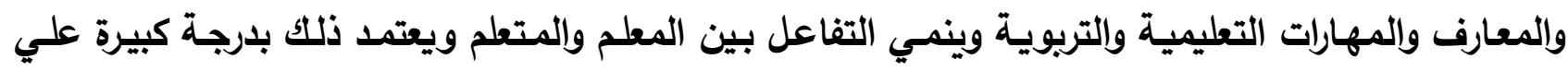

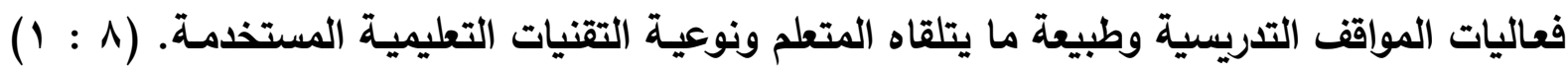
ومن هنا اتجهت البحوث والدراسـات في مجال تعليم كرة السلة إلى الاهتمـام بطرق إعداد مدربي الميني باسكت نظراً لأهمية هذة المرحلة وكونها تتطلب الكثير من العناية والجها المبنيين على مستوى تأهيل مناسب لمدربي هذة المرحلة. 
ونظرية الذكاءات المتعددة تقدم سياقاً مثاليا لإضفاء معني علي مهارات المتعلم المعرفية فالذكاءات

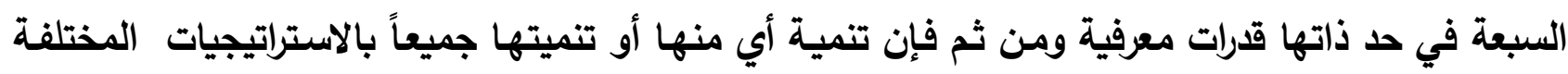

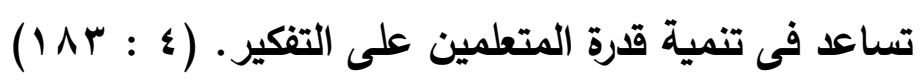

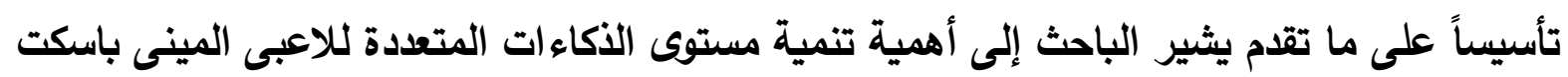

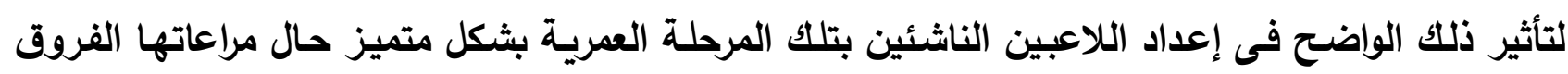

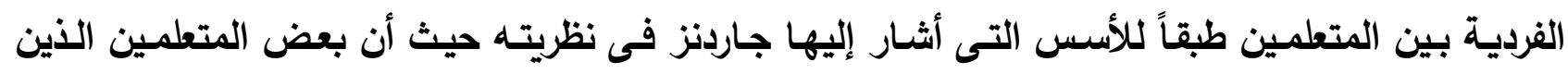
يخفقون فى تعلمهم بسبب نواحى قصورهم فى مجال ذكاء معين يستطيعون فى حالات كثيرة أن يتجنبوا هذه الهئ

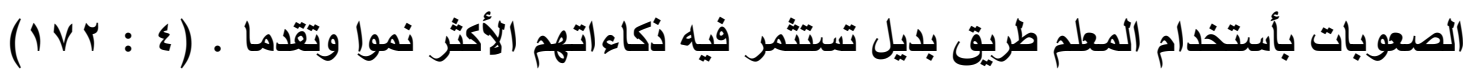

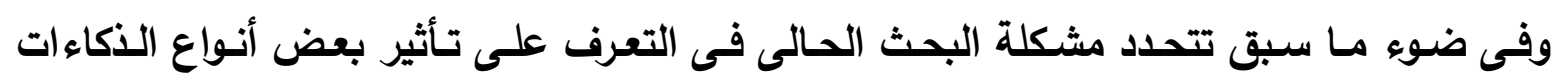

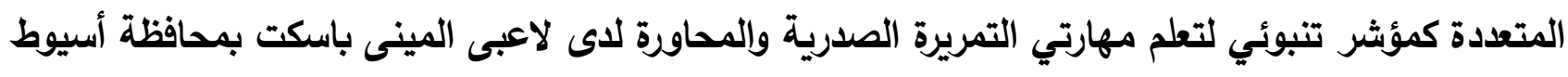

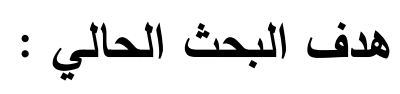

يهذف البحث الحسالي إلى التعرف على تأثير بعض أنواع الذكاءات المتعددة كمؤشر تنبوئي لتعلم مهارتي التمريرة الصدرية والمحاورة لاى لاعبى المينى باسكت بمحافظة أسيوط . فروض البحث : 1- توجد مستويـات متباينة لأنواع الذكاءات المتعددة قيد البحث لاى لاعبى المينى باسكت بمحافظة أسيوط

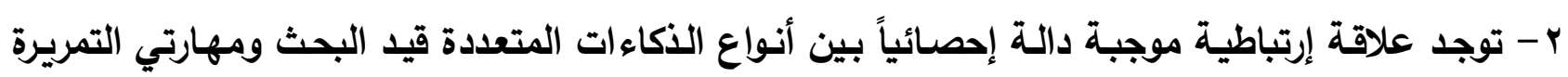
الصدرية والمحاورة للاعبى المينى باسكت بمحافظة أسيوط . ب- توجد فروق دالة إحصائيا بين لاعبي الميني باسكت المتميزين وغير المتميزين من حيث المستوى المئي

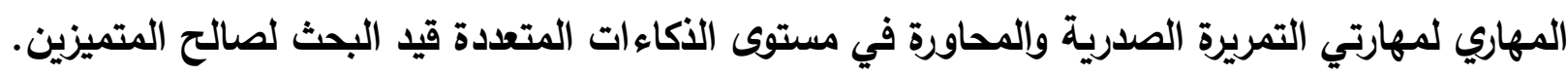

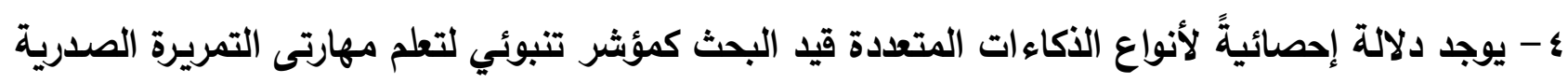
والمحاورة للاعبى المينى باسكت بمحافظة أسيوط .

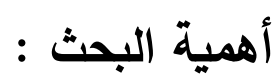
1- يعد البحث الحسالي استجابة للاتجاهـات الحديثة التـي تنـادي بضرورة الاهتمـام بنظريـة الذكاءات

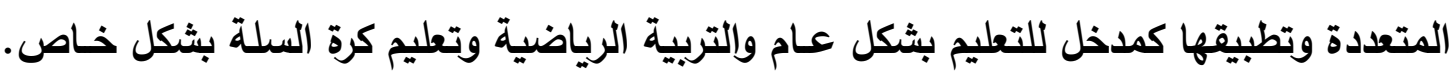

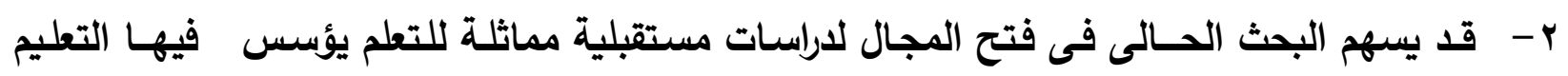

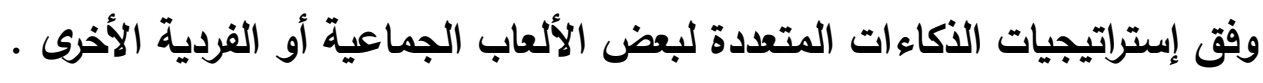

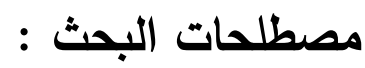
الأكاءات المتعددة : 
عرفها كلاً من "جابر عبدالحميد ץ . . ץ" ، جاردنر بـ 9 و ا" بأنها مجموعة من الذكاءات أقترحها هوارد

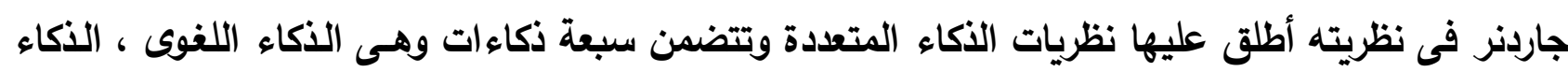

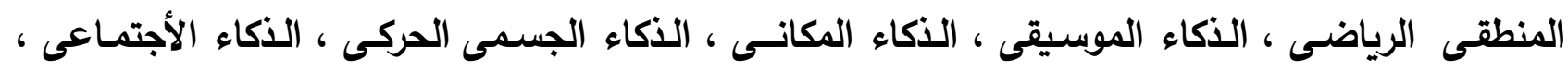

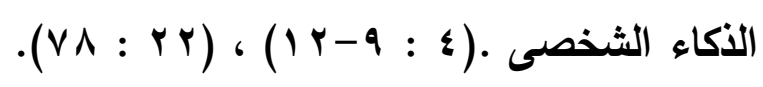

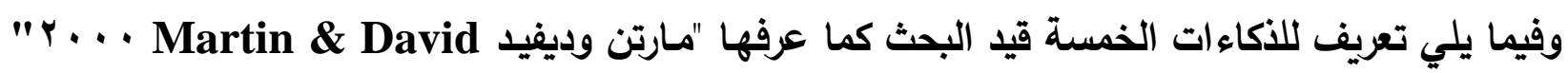

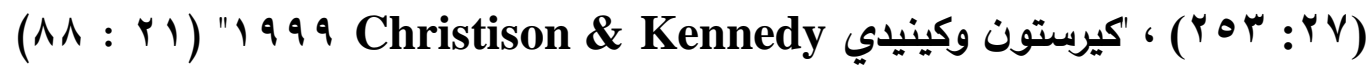

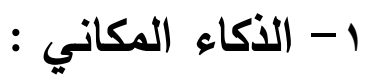
يقصد بـه القدرة على إدراك العالم البصري المكاني بدقه ويتضمن هذا الذكاء الحساسية للألهوان والخطوط والأثكال والحيز وإلعلاقات بين هذه العناصر والتصور البصري. r- الأكاء اللغوى : يقصد به القدرة على استخدام الكلمات بكفاءة شفهيا ، ويتضمن هذا الذكاء القدرة على معالجة البناء اللغوي والصوتيات والمعاني والاستخدام العملي للغة. r- الأكاء الاجتماعي يقصــ بـه القـرة على إدراك الحسالات المزاجيـة للآخـرين والتمييز بينها وإدراك نوايـاهم ودوافعهم

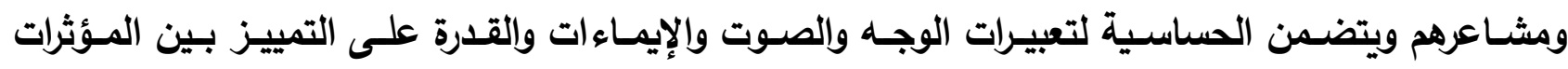

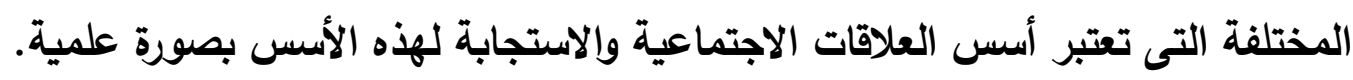

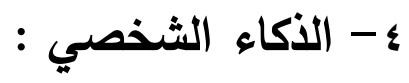
يقصد به معرفة الذات والقدرة على التصرف المتوائم مـع هذه المعرفة وأن يكون لاى الفرد صورة دقيقة عن نفسه ومعرفة جوانب القوة والضعف كذلك الوعي بحالات الفرد المزاجية الدوافع والرغبات والقدرة على الضبط الذاتي والاحترام الذاتي.

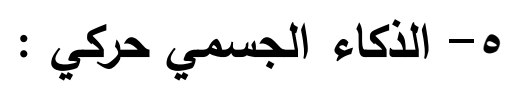
يقصد به قررة الفرد في استخدام جسمه للتعبير عن الأفكار والمشاعر ويتضمن هذا الذكاء مهارات التآزر والتوازن والمهارة والقوة والمرونة وإلسرعة. تعريف إجرائي للأكاءات المتعددة : يعرف الباحث إجرائياً الذكاءات المتعددة بأنها مجموعة الإجراءات والممارسات المرتبطة بالذكاءات الخمسة ( قيد البحث ) التى أقترحها جاردنر والتى تؤثر فى مستوى تعلـم لاعبى المينى باسكت لمهارات البات كرة السلة .

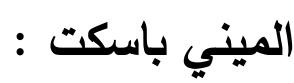


يعرفها الباحث إجرائيا بأنها أولى المراحل التعليمية في لعبة كرة السلة والتي يتم من خلالها تعليم اللاعبين

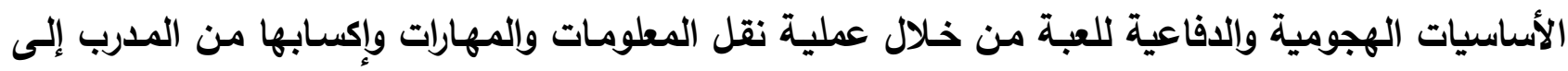
اللاعب مستخدماً الطرق والأساليب المناسبة فى عملية التعلم .

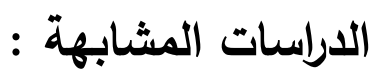

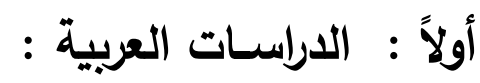

1) استهدفت الاراسـة التعرف على فاعلية أنشطة الأكاءات المتعددة فى إكتثـاف الموهوبين وأستخدم

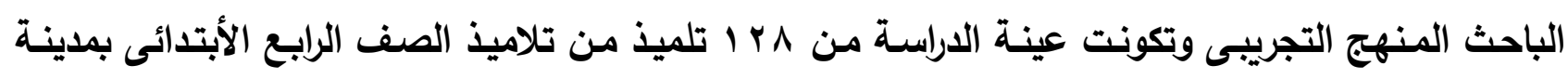

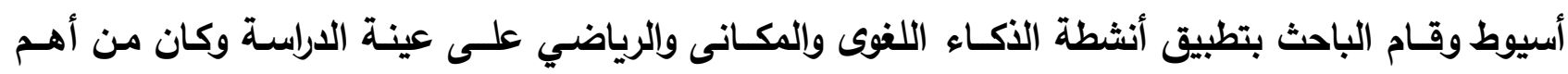
النتائج نجاح أنثطة الذكاءات المتعددة فى إكتثاف الموهوبين وتحديد مجاء الفئل الموهبة.

r) استهدفت الدراسة التعرف على فاعلية إستراتيجيات الذكاءات المتعددة في تدريس العلوم فى تنمية

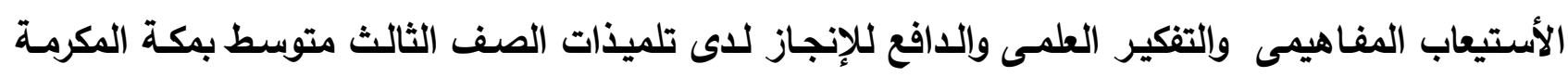

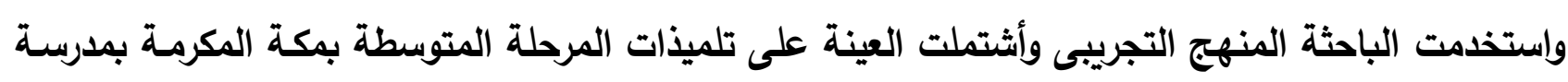

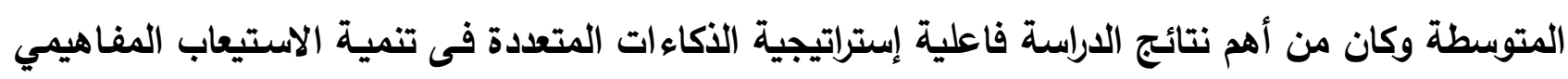
والتفكير العلمي والدافع للإنجاز.

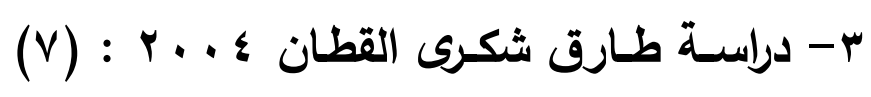

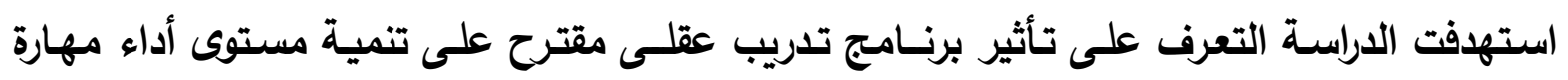

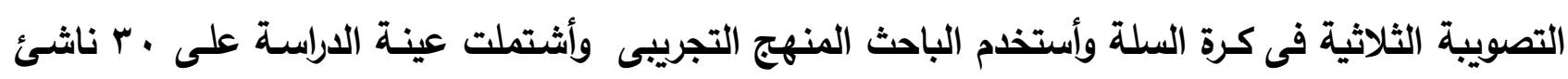

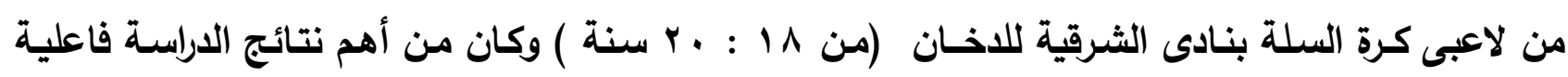

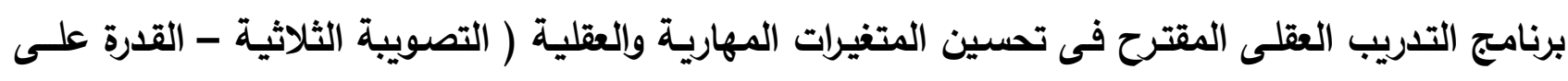

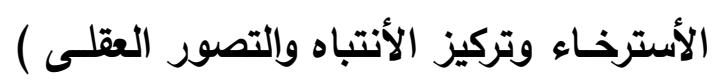

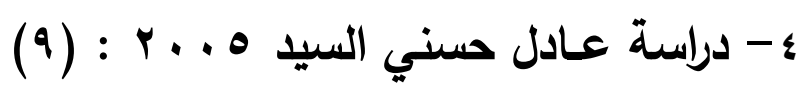
استهدفت الدراسة التعرف على تأثير برنامسج تعليمى مقترح لتنمية الإدراك الحس حركي وأثره على : التى

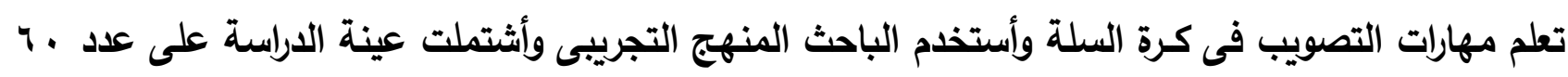

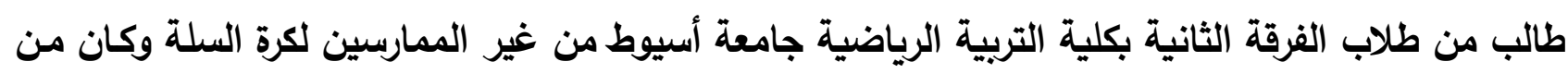

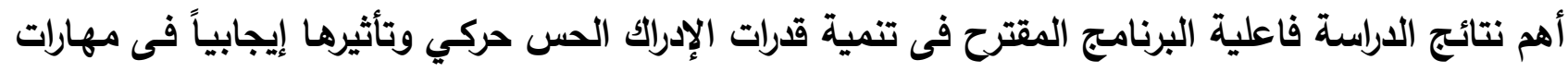
التصويب في كـرة السلة . ثانياً : الدراسات الأجنبية :

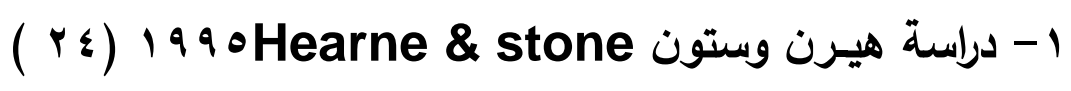


استهافت الدراسـة التعرف على إمكانية رفع مستوى التحصيل الدراسى لدى الأطفال ذوى صعوبات

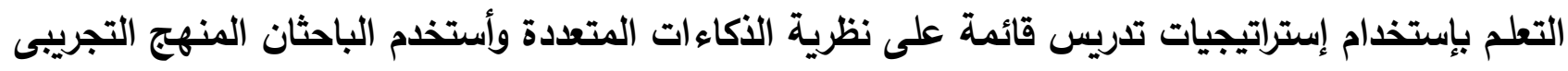

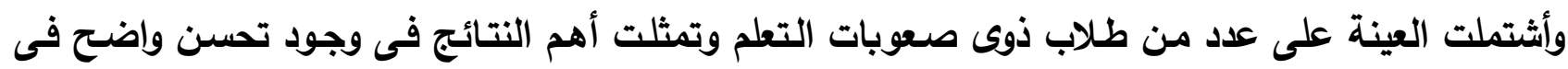

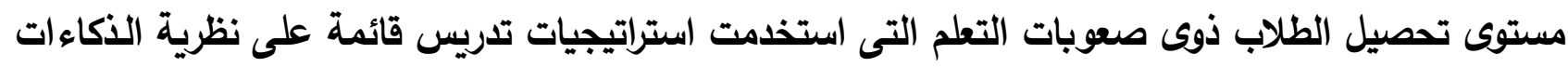
المتعددة مقارنة بأساليب التدريس التقليدية .

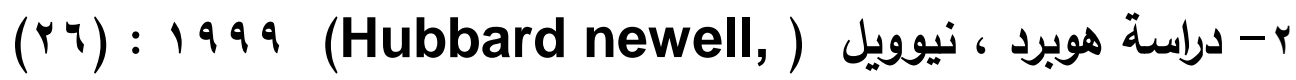

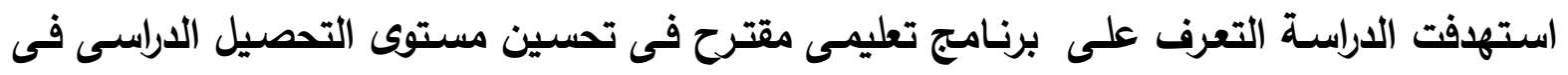

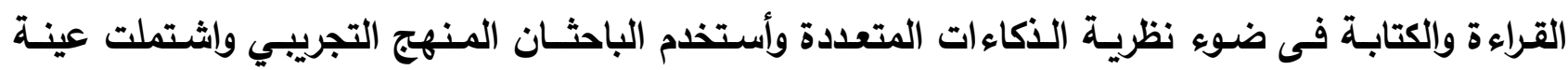

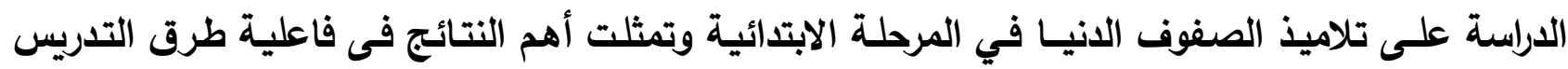
القائمة على نظرية الذكاءات المتعددة فى تحسين مستوى التحصيل الدراسي في القراءة والكتابة ، كذللك أنها تراعى الفروق الفردية بين التلاميذ .

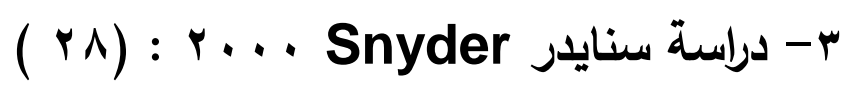
استهافت الدراسـة فحص العلاقة بين كل من أسـاليب التدريس التقليدية وغير التقليدية ومستوى

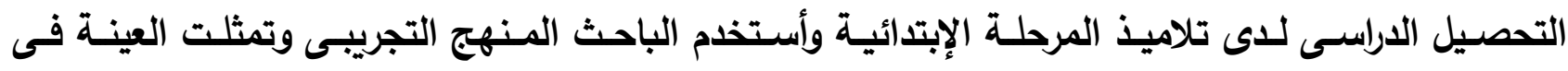

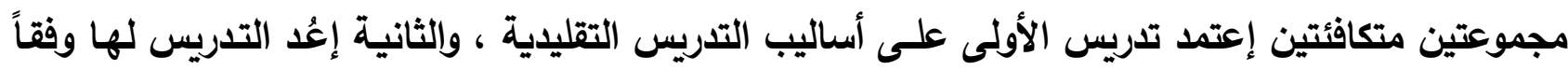

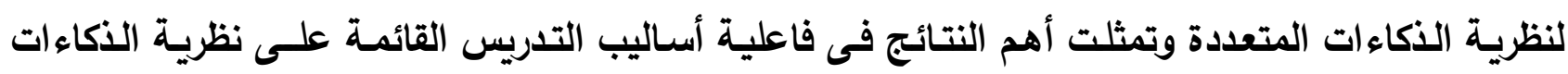
المتعددة فى رفع مستوى التحصيل الاراسى للمجموعة التجريبية .

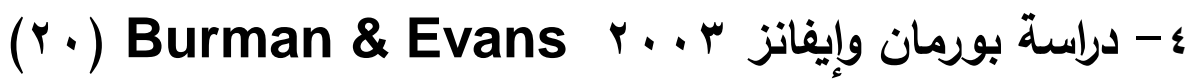
استهدفت الدراسة تحسين مهارات القراءة لاى عينة من تلاميذ المرحلة الإبتدائية من ذوى صعوبات

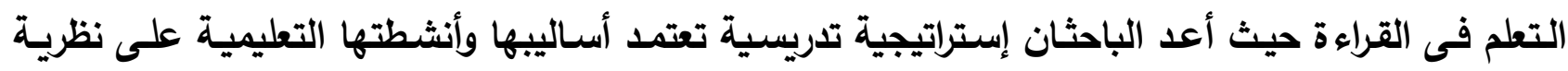

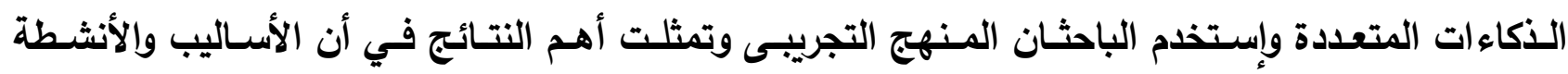
التعليمية التى تقوم على نظرية الذكاءات المتعددة أدت إلى تحسن ملحوظ فى القياس البعدى لمهارات القراءة

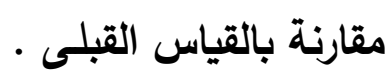
- التعليق على الدراسات السابقة : رغم اختلاف الدراسات السابقة فى أهدافها وتوجهاتها إلا أن غالبيتها أشارت إلى الدراسات التى قامت

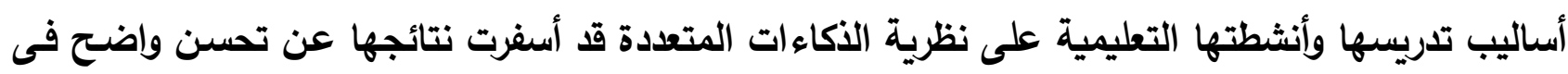

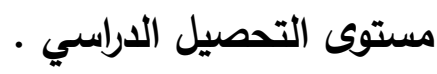

كمـا يتضح من نتائج تلك الاراسات أن أساليب التدريس القائمة على نظرية الاكاءات المتعددة تسمح لكل متعلم بأن يتعلم من خلال الأنثطة التعليمية التي تتوافق مع الذكاء المرتفع لايه من ذكاءاتهه المتعددة ، 
كنلك تؤكد نظرية الذكاءات المتعددة بأن يكون المعلم حريص على التنويع فى المواقف والأنشطة التعليمية

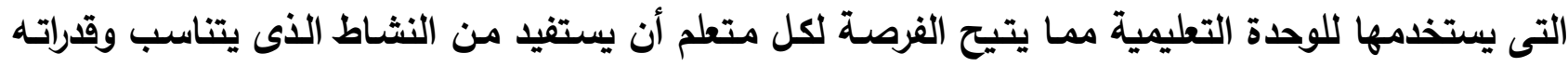
وإمكاناته .

في حدود علم الباحث تختلف الاراسـة الحالية عن الدراسـات السـابقة كونها أولى الدراسـات التى تستخدم نظرية الذكاءات المتعددة لجاردنر في مجال التربية الرياضية كمؤشر تنبوئي لتعلم مهارتي التمريرة

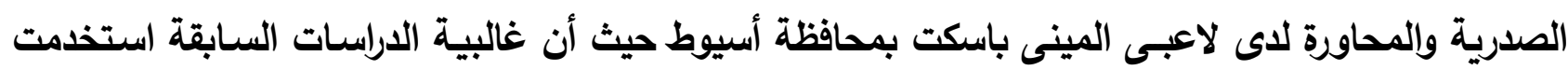

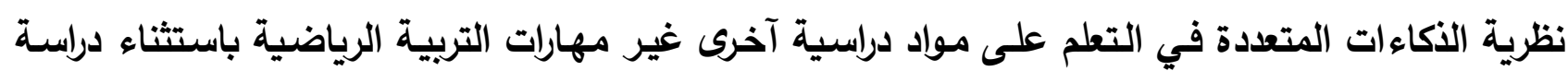
طارق شكري (V) التي استهدفت التعرف على تأثير برنـامج تدريب عقلى مقترح على تنمية مستوى أداء

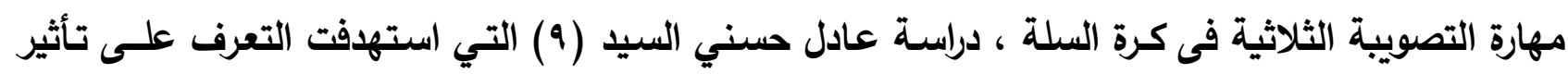
برنامـج تعليمى مقترح لتنمية الإدراك الحس حركي وأثره على تعلم مهارات التصويب فى كرة السلة.

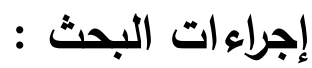

المنهج المستخدم : إستخدم الباحث المنهج الوصفي لمناسبته وطبيعة البحث. عينة البحث : ميث

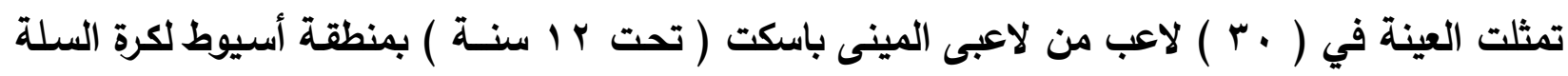

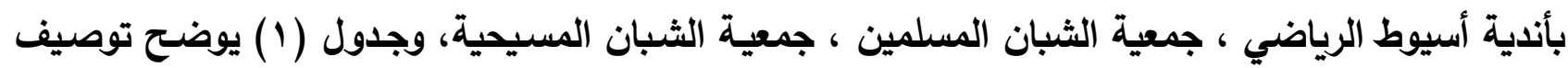
عينة البحث.

جدول (1)

توصيف عينة البحث

\begin{tabular}{|c|c|c|}
\hline العدد الع & النادي & م \\
\hline 1. & أسيوط الرياضي & 1 \\
\hline 1. & الشبان المسلمين & r \\
\hline 1. & الثبان المسيحية & $r$ \\
\hline
\end{tabular}


أولاً : إستبيان تقدير الأكاءات المتعددة :

قـام الباحث بإعداد استبيان قياس نمو الذكاءات المتعددة للاعبى المينى باسكت فى خمس أنواع من

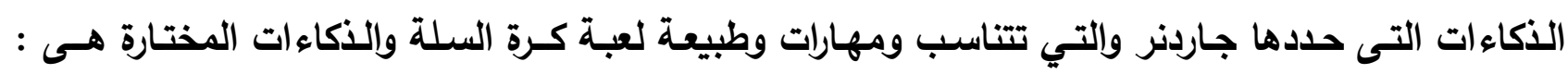

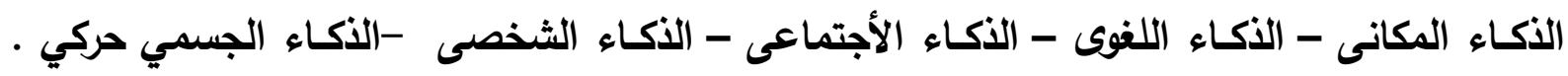
1- تحديد الهدف من الأستبيان :

يهدف الاستبيان إلى قياس بعض أنواع الذكاءات المتعدة لدى لاعبى المينى باسكت بمنطقة أسيوط

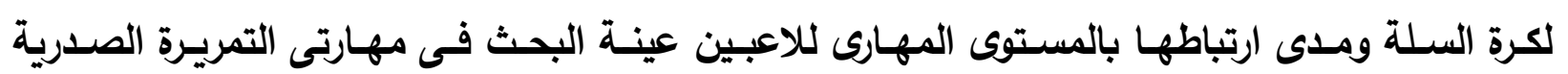
والمحاورة.

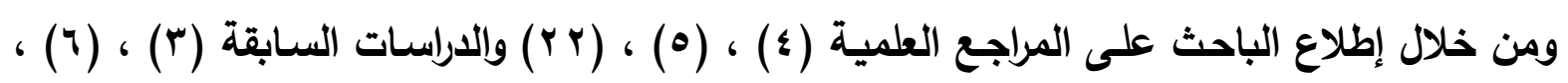

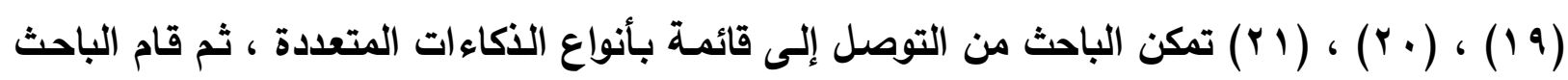

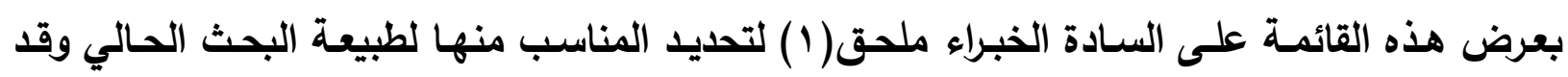

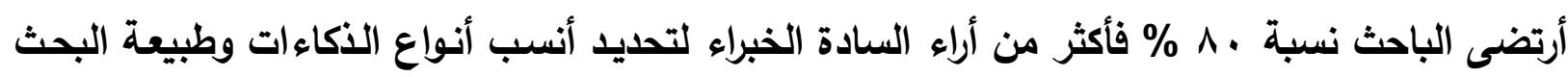
الحالي وجدول (r) يوضح ذلك.

\section{جدول (ץ)}

يوضح الأهمية النسبية لأنواع الذكاءات المتعددة لجاردنر في ضوء طبيعة البحث الحالي

\begin{tabular}{|c|c|c|}
\hline الأهمية النسبية & الأكاء & م \\
\hline$\% 1 \ldots$ & الأكاء المكاني & 1 \\
\hline$\% 1 \ldots$ & الذكاء اللغوي & r \\
\hline$\%$ r. & الأكاء المنطقي الرياضي & $r$ \\
\hline$\% \wedge$ & الأكاء الاجتماعي & $\varepsilon$ \\
\hline$\% 1 \ldots$ & الأكاء الشخصي & 0 \\
\hline$\% \varepsilon$. & الأكاء الموسيقي & 9 \\
\hline صفز \% & الأكاء الوجودي & $v$ \\
\hline$\% 1 \ldots$ & الأكاء الجسمي حركي & $\wedge$ \\
\hline صفر \% & الأكاء المتعلق بالطبيعة & 9 \\
\hline
\end{tabular}


يوضح جدول (r) حصول كلا من الذكاء المكاني واللفوي والثخصي والجسمي حركي على نسبة

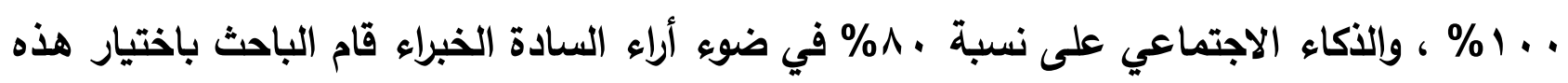

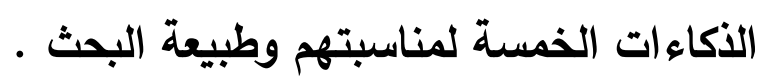
ب - كتابة مفردات الاستبيان : قام الباحث بكتابة أسئلة مفردات الاستبيان على نمط الأختبار الموضوعى وروعى عند صياغة المفردات ما يلى :

- أن تتناسب المفردات ومستوى لاعبى كرة السلة تحت ب اسنة . - ارتباط المفردات بأهداف الأستبيان - ألا تثير المفردات إلى اتجاه للإجابة .

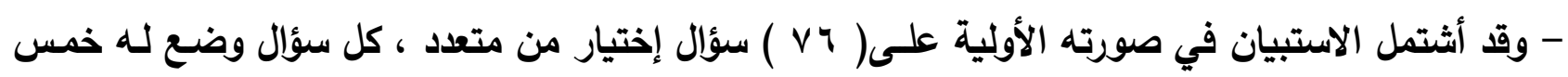

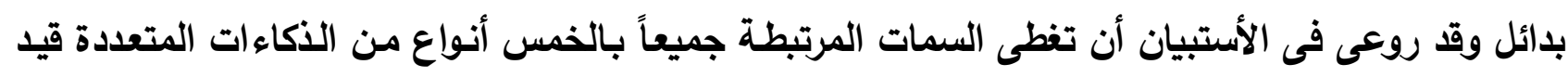

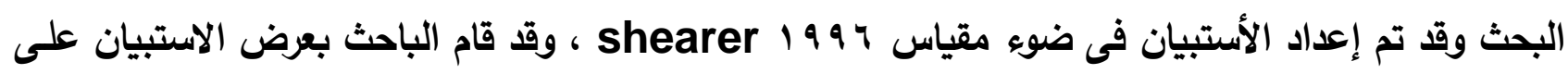

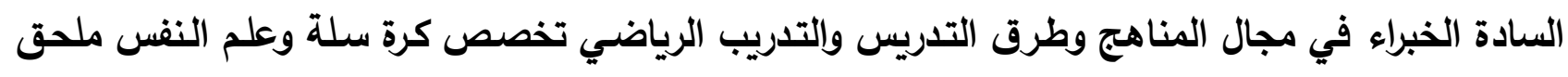

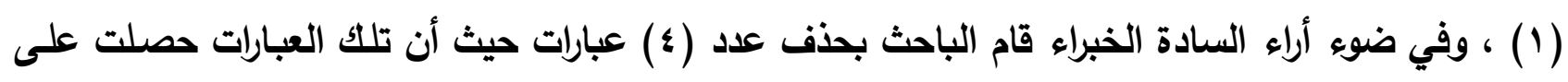

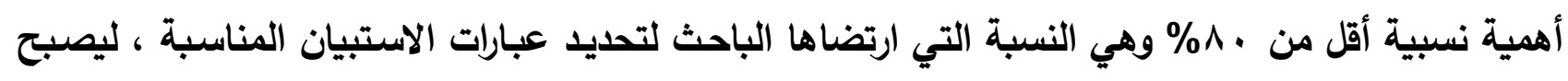

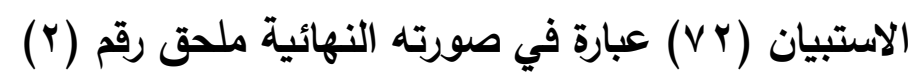
جدول (r) جاءو (r)

استبيان تقدير مستوى الأكاءات المتعددة للاعبي الميني باسكت في صورته الأولية

\begin{tabular}{|c|c|c|}
\hline الالأهبية & عبارات الذكاء المكاني & b \\
\hline$\% \wedge$. & مـا مدى إتقانك لتدريبات نط الحبـل . & 1 \\
\hline$\% 1 \ldots$ & هل تتؤدى التدريبات المهارية والبدنية باستخدام الأقمـاع والحواجز بدقة وسهولـة . & r \\
\hline$\% 1 \ldots$ & هل تستطيع القيـام بتركيب شبكة الهاف. ل & $r$ \\
\hline$\% 1 \ldots$ & ما مدى إتقاتك فى اتخاذ الأماكن المناسبة هجومـاً ودفاعاً . . & $\varepsilon$ \\
\hline$\% \wedge$. & هل تستطيع ضبط وضع الهدف ( برج السلة ) في مكانة الصحيح . & 0 \\
\hline$\% \wedge$. & هل بإمكانك إصابة الهذف بنسبة عالية باستخذام لوحه الهدف . & 9 \\
\hline$\% 1 \ldots$ & هل تستخدم المكان الأفضل لإخراج الكرة بعد إصابة الهدف بعيداً عن تواجد المنافسين . & $\mathrm{v}$ \\
\hline$\% 1 \ldots$ & هل تجيد الوقوف فى المكان الأفضل لاستلام الكرة من الحكم خارج الملعب وبعيداً عن المنافسين & $\wedge$ \\
\hline$\% 1 \ldots$ & ما مدى إتقانك فى المرور بالكرة وبدونها فى المساحات الضيقة بين المنافسين ـ . & 9 \\
\hline$\% \wedge$. & ما مدى إتقانك فى إتباع التحركات الخططية فى المرات الأولى لتعلمها . & 1. \\
\hline$\% r$. & هل بإمكانك إصابة الهـف من خارج قوس الرمية الثلاثية & 11 \\
\hline
\end{tabular}


تابع جدول (r)

استبيان تقدير مستوى الذكاءات المتعلدة للاعبي الميني باسكت

في صورته الأولية

\begin{tabular}{|c|c|c|}
\hline الالأهميية & 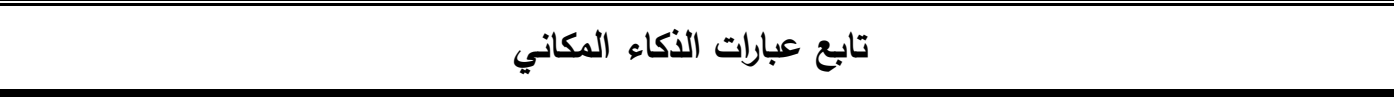 & م \\
\hline$\% \wedge$. & هل تلاحظ ما قد يطرأ على تغيير قانونية الملعب والأهداف. & ir \\
\hline$\% 1 \ldots$ & هل تستخدم المكان المناسب لحجز المدافع ليكون نقطة انطلاق جيدة لاستلام الكرة . & ir \\
\hline$\% \wedge$. & هل تستطيع أن تثارك المدرب فى رسم أو تلوين ملعب كرة السلة . . & $1 \leq$ \\
\hline$\% \wedge$. & هل ترى أن لايك ذوقاً فنياً فى حال تصميم ودهان ملعب كرة السلة . & 10 \\
\hline$\% 1 \ldots$ & هل لايك حس جيد للاتجاهات داخل وخـارج ملعب كرة السلة بالملاعب التى تثارك بها لأول مـرة . & 17 \\
\hline الالأهميية & عبارات الأكاء اللغوي & 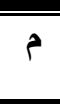 \\
\hline$\% 1 \ldots$ & هل تستمتع بسرد وتناول المدرب تاريخ ونثأة كرة السلة . & iv \\
\hline$\% \wedge$. & هل تستخذم درجـات صوت مختلفة مع زملائك بالفريق تختلف باختلاف مكانك & 11 \\
\hline$\% \leq$. & هل تعلم متى نشأت كرة السلة ومن هو مؤسسها & 19 \\
\hline$\%$ r. & هل ترى أن لايك محتوى معرفي جيد عن مهارات كرة السلة في مستوى الفريق الأول & r. \\
\hline$\% 1 \ldots$ & هل ترى من المفيد اختلاف صوت المدرب فى المباريات عنه فى التدريب . ل & Y \\
\hline$\% \wedge$. & هلتصل تستخدم التعبيرات اللغوية المعبرة عن مهارات كرة السلة ومواقف اللعب بثكل جيد (العاب القطع والحجز & rr \\
\hline$\% 1 \ldots$ & هل أنت متحدث قـادر على الإقناع بين زملائك بالفريق . . & rr \\
\hline$\% 1 \ldots$ & كيف تقيم نفكك فى القدرة على إجراء الحوار مع زملائك بشأن أمور الفريق . & r \\
\hline$\% 1 \ldots$ & هل تستطيع إقناع زملائك بأرائك خلال بعض المناقشات . . مل & ro \\
\hline$\% 1 \ldots$ & هل تستطيع إقناع زملائك بأن ينفذوا بعض التحركات الهجومية والدفاعية بالطريقة التي تريدهـا & r \\
\hline$\% 1 \ldots$ & هل لديك اهتمام أو متعة فى الحديث عن مباريات كرة السلة في البطولات العالمية . . & rV \\
\hline$\% 1 \ldots$ & هل أنت اللاعب الذى يطلب منه الحديث عن فريقك في حفلات ختام النشاط . . & rᄉ \\
\hline$\% \wedge$. & هل بإمكانك تقليد الطريقة التى يتحدث بها مدربك أو الحكام . . & rq \\
\hline$\% \wedge$ & هل ترى أن لايك محتوى معرفي جيد عن المهارات التى تعلمتها . & $r$. \\
\hline$\% 1 \ldots$ & هل لايك مهارة التحدث بوضوح واختيار الكلمات المناسبة . . & r \\
\hline الألهميية & عبارات الأكاء الاجتماعي & b \\
\hline$\% \wedge$. & هل لايك صداقات دامت لفترة طويلة داخل أو خارج فريقك. & rr \\
\hline$\% \wedge$. & هل تستطيع نشر الهدوء والتفاهم داخل الفريق. & rr \\
\hline$\% \wedge$. & هل يتم اختيارك أحيانا رئيس فريق (كابتن) & $r \varepsilon$ \\
\hline$\% 1 \ldots$ & في النادي هل أنت عادة جزء من جماعة أو هواية معينة. & ro \\
\hline$\% 1 \ldots$ & هل تتفهر مشاعر ورغبات زملائك بالفريق بسهولة. & q \\
\hline$\% 1 \ldots$ & هل تقوم بالمساعدة في إحضار أدوات التدريب وإرجاعها مرة آخري. & rv \\
\hline$\% 1 \ldots$ & هل يأتي إليك بعض زملائك بالفريق للتحدث عن مشكلاتهم الثخصية. & $\mu \wedge$ \\
\hline
\end{tabular}


تابع جدول (r)

استبيان تقدير مستوى الذكاءات المتعلدة للاعبي الميني باسكت

في صورته الأولية

\begin{tabular}{|c|c|c|}
\hline النسبيتية & تابع عبارات الأكاء الاجتماعي & r \\
\hline$\% \wedge$. & ما مدى قدرتك في الحكم على شخصيات من حولك. & rq \\
\hline$\% 1 \ldots$ & هل تعرف كيف تجعل زملائك بالفريق يشعرون بالطمأنينة والارتياح. & $\varepsilon$. \\
\hline$\% 1 \ldots$ & هل تستمع لنصائح مدربك وزملائك. & $\leqslant 1$ \\
\hline$\% 1 \ldots$ & هل أنت تشعر بالارتياح بصفة عامة بين زملائك بالفريق. & $\varepsilon \varphi$ \\
\hline$\% 1 \ldots$ & هل ترى أنك شخص يسهل على أعضاء النادي معرفته ومصادقته. & $\varepsilon r$ \\
\hline$\% 1 \ldots$ & هل تصادفك أوقات صعبة في التأقلم مع بعض زملائك بالفريق أو أعضاء النادي. & $\varepsilon \varepsilon$ \\
\hline$\% 1 \ldots$ & قبل بدء التدريب هل تفضل اللعب بمفردك. & $\leqslant 0$ \\
\hline الالأهبية & عبارات الأكاء الشخصي & r \\
\hline$\% 1 \ldots$ & هل لديك إحسـاس واضح بذاتك داخل الفريق وإحساس بتحقيق ما تريده بتعلم لعبة كرة السلة . & $\leqslant 4$ \\
\hline$\% 1 \ldots$ & هل أنت قادر على التحكم فى انفعالاتك حسال ارتكاب خطأ بقوة ضدك من المنافس . & $\varepsilon V$ \\
\hline$\% 1 \ldots$ & هل تقوم بالعمل والمثابرة لتحقيق هدفك لتكون لاعب أساسي بفريقك . . & «^ \\
\hline$\% 1 \ldots$ & هل تجيد اتخاذ القرار المناسب للتظلب على دفاعات المنافس . & $\leq 9$ \\
\hline$\% 1 \ldots$ & هل أنت سعيد في مركزك الدفاعي الذي أختاره مدربك للك لأنه يتناسب وقدراتك ومهاراتك. & $\therefore$. \\
\hline$\% 1 \ldots$ & هل تثعر بالسعادة في تخصصك ( صـانع لعب مثلاً ) لمناسبته ومهاراتك . . & 01 \\
\hline$\% 1 \ldots$ & هل تعلم المهارات الهجومية التى تتميز فيها والتى لا تتميز فيها وتحاول أن تطور من مستواك بها . & or \\
\hline$\% 1 \ldots$ & هل ينتابك الغضب عندمـا يخسر فريقك المبـاراة . & r \\
\hline$\% 1 \ldots$ & هل لايك الاهتمام فى تحسين مستوى مهاراتك بحضور تدريبات الفريق الأعلى سناً أو مشاهدة مباريات الدرجة الأولى & ๑ \\
\hline$\% 1 \ldots$ & هل أنت قادراً داخل فريقك على إيجاد طرق منفردة لحل مشاكلك الثخصية أو الفنية & 00 \\
\hline النسبية & عبارات الأكاء الجسمي حركي & b \\
\hline$\% 1 \ldots$ & هل تستمع بالألعاب الرياضية داخل صالات النثاط المدرسية أكثر من المواد التعليمية داخل الفصل. & 04 \\
\hline$\% 1 \ldots$ & هل تمارس بعض الرياضات الأخرى غير كرة السلة السلة بالنادي أو العدرسة . . & ov \\
\hline$\% 1 \ldots$ & هل سبق لك الانضمام لفريق المدرسة لكرة السلة . & $\Delta \wedge$ \\
\hline$\% 1 \ldots$ & هل تمارس بعض التمارين البدنية بالمنزل . & ०9 \\
\hline$\% 1 \ldots$ & هل تجيد استخدام الأصابع خلال عملية المحاورة . & 9. \\
\hline$\% 1 \ldots$ & 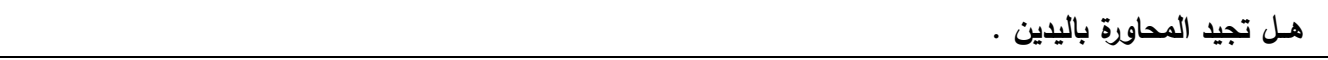 & 71 \\
\hline$\% 1 \ldots$ & هل بإمكاتك عمل دوران بالكرة على أصبع السبابة . & 4 \\
\hline$\% 1 \ldots$ & هل تحافظ على توازن جسمك خلال المحاورة والمراوغة بين المدافعين أو الأقماع & r \\
\hline$\% \wedge$ & هل تندفع خارج الملعب عقب التصويب السلمى . ماري & $7 \varepsilon$ \\
\hline$\% \wedge$. & ما مدى إتقانك التمريرة الصدرية بأداء سريع على الدوائر المرسومة على الحائط. & 10 \\
\hline$\% 1 \ldots$ & هل تجيد استخدام جسمك في خداع الددافين للوصول للهيف بسهولة. & 74 \\
\hline$\% ч$. & هل تجيد عمل ألعاب استعراضية مثل فريق هارئم & IV \\
\hline
\end{tabular}


تابع جدول (r) (ب) (باء)

استبيان تقدير مستوى الأكاءات المتعددة للاعبي الميني باسكت

في صورته الأولية

\begin{tabular}{|c|c|c|}
\hline الأهميبة & تابع عبارات الأكاء الجسمي حركي & b \\
\hline$\% 1 \ldots$ & هل لايك توازن جيد خلال أدائك التمريرة الصدرية والتصويب السلمي. & $\uparrow 1$ \\
\hline$\% 1 \ldots$ & هل تتعلم بسهولة من خلال أداء المدرب لنموذج الأداء . . & 79 \\
\hline$\% 1 \ldots$ & هل تؤدى مهارة المحاورة بشكل إنسيابى دون تشنج . & $v$. \\
\hline$\% 1 \ldots$ & هل تقوم بمتابعة التمرير الصدرية بد الذراعين بعد دفع الكرة بالأصابع. & $v_{1}$ \\
\hline$\% 1 \ldots$ & هل تحافظ على رؤية جيدة للملب أثناء أداء مهارة المحاورة . & vr \\
\hline$\% 1 \ldots$ & هل تنوع فى مستوى تنطيط الكرة تبعاً لوضع الددافعين وموقعك الهجومى & vr \\
\hline$\% 1 \ldots$ & هل تقوم بعمل الحماية اللازمة باليد المقابلة أثناء المحاورة . & $v \varepsilon$ \\
\hline$\% 1 \ldots$ & هل تؤدى التمريرة الصدرية بحيث تتقدم إحدى القدمين خطوة فى اتجاه الكرة . & vo \\
\hline$\% 1 \ldots$ & هل يختلف مستوى إتقانك التمريرة الصدرية باختلاف المسافة . & v \\
\hline
\end{tabular}

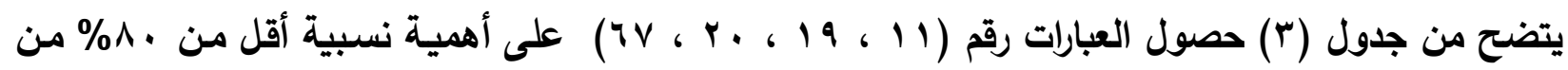
أراء السادة الخبراء ولذلك قام الباحث بحذفها من الاستبيان.

- ولبيـان كيفية الإجابة عن أسئلة الأستبيان قـام الباحث بإعداد وتحديد تعليمـات الأستبيان روعى فيها سهولة ودقة الألفاظ وتضمنت كيفية الإجابة عن أسئلة الأستبيان .

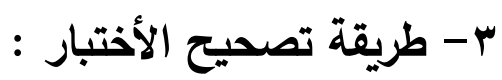
للتأكد من موضوعية الأستبيان قام الباحث برصد درجة واحدة للإختيار ( لا ) ودرجتان للاختيار ( بدرجة

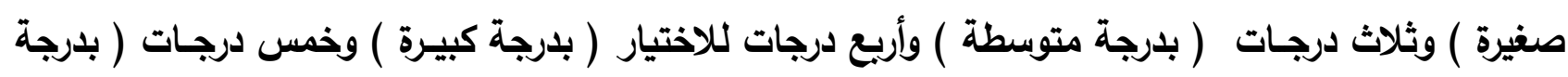

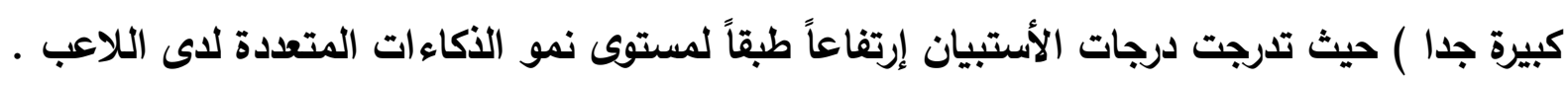
צ- زمسن الاختبار : تم تحديد زمن تطبيق الاستبيان من خلال تطبيقه على العينة الاستطلاعية بعد إجراء بعض التعديلات وفقا

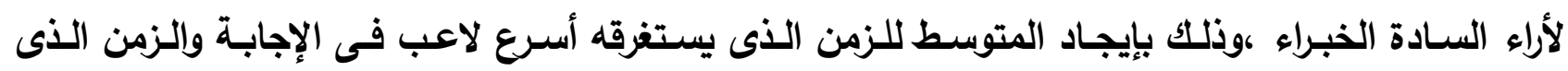
يستغرقه أبطأ لاعب وعليه حدد زمن الإجابة على الاستبيان وقدرة ( • ) دقيقة وبذلك أصبح الاستبيان جاهـز للتطبيق فى صورته النهائية ملحق (r) 
المعاملات العلمية لاستبيان الأكاءات المتعددة : للتأكد من صدق استبيان الذكاءات المتعددة قام الباحث بحساب الصدق العاملي : حيث تم تطبيق الاستبيان على أفراد العينة الاستطلاعية والذين بلغ عدد أفرادها ( ) لاعب من لاعبى المينى باسكت بمنطقة أسيوط لكرة السلة من خارج العينة الأصلية للبحث ، وذلك للتأكد من توافر الثروط السيكومترية للاستبيان ، وللتأكد من الصدق العاملي للاستبيان تم استخدام طريقة التحليل العاملي لمعرفة المكونات الرئيسية للظواهر التي نخضعها للاستبيان ، ويعد أفضل وأدق أنواع الصدق ، كما اعتمد الباحث على استخدام طريقة المكونات الأساسية والتدوير باستخدام طريقة الفاريماكس Varimax والاعتماد على محك أو معيار كايزر Kaiser من خلال برنامج SPSS ، ويوضح جدول رقم (؛) مصفوفة العوامل النهائية بعد عملية التدوير المتعامدة . معير مايرد

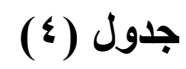

يوضح مصفوفة العو امل لأبعاد مقياس الذكاءات المتعددة بعد التدوير المتعامد وبعد حذف التثبعات الصغيرة

\begin{tabular}{|c|c|c|c|c|c|c|c|c|c|}
\hline \multicolumn{10}{|c|}{ العوامل } \\
\hline \multicolumn{2}{|c|}{ الأكاء الجسمي حركي } & \multicolumn{2}{|c|}{ الأكاء الثخصي } & \multicolumn{2}{|c|}{ الأكاء الاجتماعي } & \multicolumn{2}{|c|}{ الأكاء اللغوي } & \multicolumn{2}{|c|}{ الأكاء المكاني } \\
\hline التشبعات & العبارات & التشبعات & العبارات & التشبعات & العبارات & التشبعات & العبارات & التشبعات & العبارات \\
\hline rr. & عبارة ؛ـ & .. $\leqslant 1$ & عبارة ه ؛ & . or & عبارة 9 ץ &.$r \Lambda$ & عبارة 19 & $\cdot . v$ & عبارة 1 \\
\hline. .09 & عبارة هـ & ס . . & عبارة 4 ؛ & .7 & عبارة · r &. .09 & عبارة V ع &. $.7 \mathrm{~V}$ & عبارة r ع \\
\hline $.0 \leqslant$ & ع ع ع v v & .0 & عبارة V ؛ & צ & عبارة ا ب &. .00 & عبارة 11 &. .74 & عبارة r \\
\hline ז7.. & عبارة ^هـ & . . & عبارة 9 ؛ & . & ع r r r r & $.0 r$ & عبارة 19 & . . & عبارة ؛ \\
\hline $.0 r$ & عبارة 9ه & r & عبارة 1 ه &. .09 & عبارة rr & $.0 \leqslant$ & 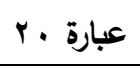 & $\cdots \leqslant V$ & عبارة ه \\
\hline . . $\leqslant 4$ & عبارة · & - & - & .70 & عبارة § & $\cdots \leqslant r$ & عبارة I r &..$\leqslant 4$ & عبارة 1 \\
\hline$\cdots \leqslant 7$ & عبارة ri & - & - & צ & عبارة هـ & - & عبارة r r r & .74 & ع عبارة v \\
\hline$\cdots \varepsilon$ & عبارة ء & - & - &. $.7 \mathrm{~V}$ & عبارة بr &. .00 & عبارة r r & - & عبارة 1 \\
\hline$\cdots \leqslant r$ & عبارة 17 & - & - & . vo & 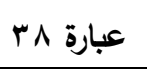 & $\ldots \leq \varepsilon$ & عبارة ع r & .. $\leqslant 1$ & عبارة 9 \\
\hline. .01 & عبارة VV & - & - & .01 & عبارة • ع & .7 & عبارة هr & . .rr & عبارة · 1 \\
\hline.$r$ & عبارة 1 & - & - & .74 & عبارة r ع &. .79 & عبارة צr &. $.0 r$ & عبارة 11 \\
\hline.$r \mu$ & عبارة 79 & - & - & - & - & $\cdots \leqslant 0$ & ع ع ع rv &. . TO & عبارة r 1 | \\
\hline $.7 \varepsilon$ & عبارة V v & - & - & - & - &.$r$. & ع ع ع r & .01 & عبارة r| 1 \\
\hline$\cdots \leqslant 0$ & ع ع ع v & - & - & - & - & - & - &..$v$ & عبارة ؛ 1 \\
\hline
\end{tabular}




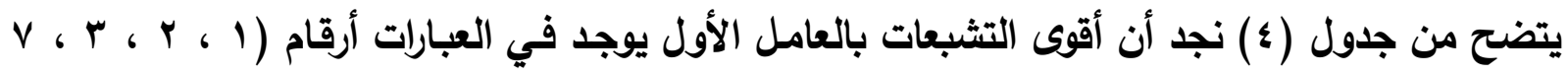

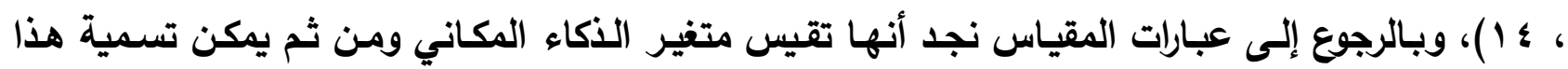

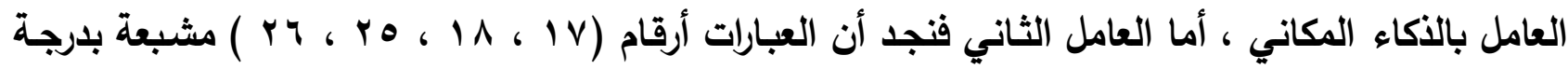

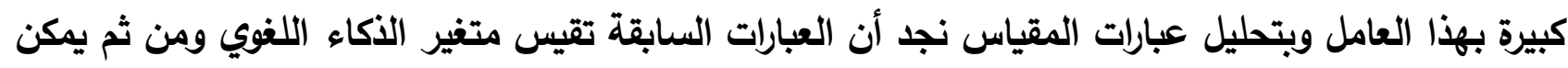

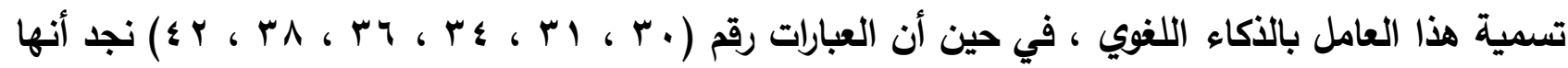

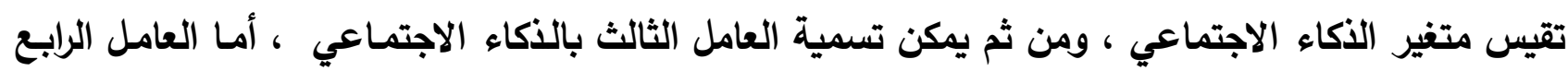

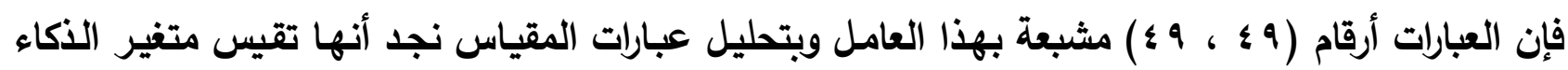

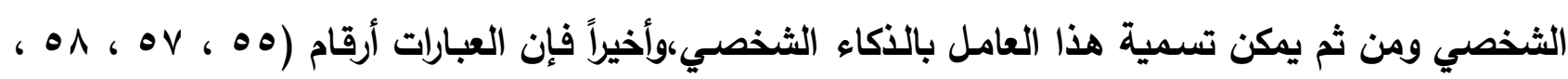

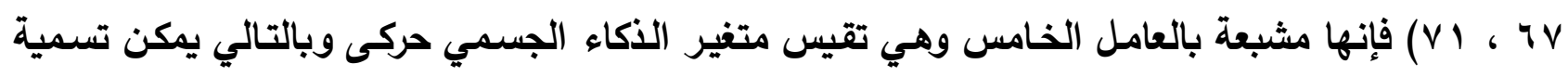
العامل الخامس بالذكاء الجسمي حركي.

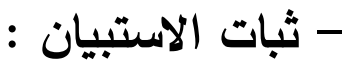
تم حساب ثبات استبيان الذكاءات المتعددة من خلال حساب معامل ألفا كرونباخ حيث قام الباحث بحساب

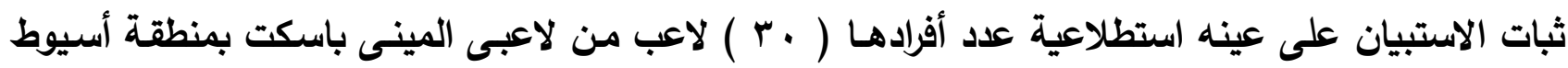

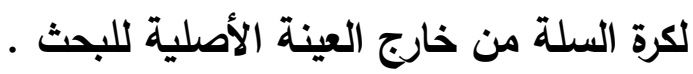

جدول (•)

يوضح معامل ثبات الاستبيان ككل ومستويات الدلالة الإحصائية.

\begin{tabular}{|c|c|c|}
\hline \multirow{2}{*}{ مستوى الدلالة } & الاستبيان ككل & الاستبيان \\
\hline & $V r=\dot{ }$ & معامل الثبات \\
\hline$\ldots 1$ & $.0 r$ & مل ألفا كرونباخ \\
\hline
\end{tabular}

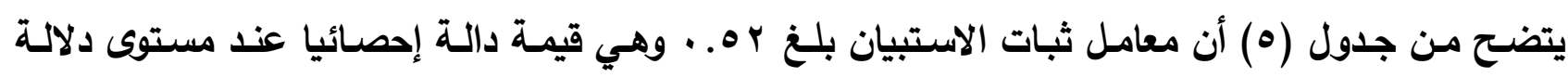

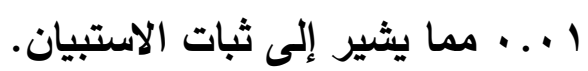

ثانياً : الأختبارات المهارية المستخدمة : ملحق (r)

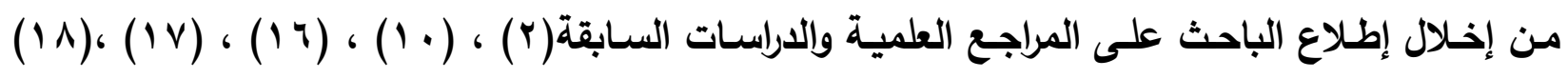

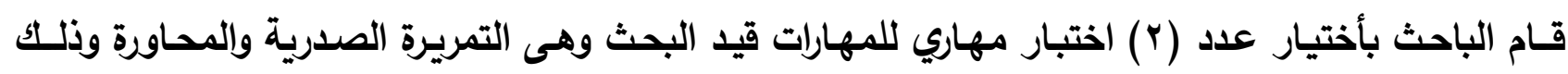

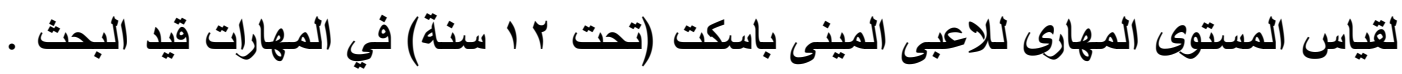
وقد قام الباحث بإيجاد المعاملات العلمية للأختبارات المهارية المستخدمة . 


\section{المعاملات العلمية للاختبارات المستخدمة : صدق الاختبارات المهاريـة : صدهات}

للتحقق من صدق التمايز في الاختبارات المهاريـة المستخدمة بين مجموعتين من اللاعبين من

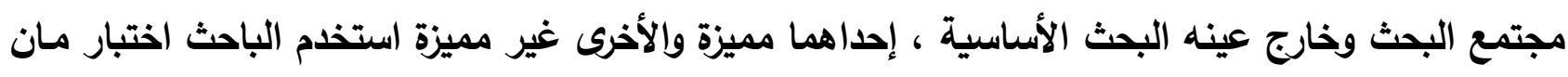
ويتني Mann-Whitney للتحقق من وجود فروقا واختلافات حقيقية بين المجموعتين.

جدول (7)

صدق التمايز للاختبارات المهارية (ن = • • (r)

\begin{tabular}{|c|c|c|c|c|c|c|}
\hline \multirow[b]{2}{*}{ مستوى الدلالة } & \multirow[b]{2}{*}{ قيمة (Z) } & \multicolumn{2}{|c|}{ مجموع الرتب } & \multicolumn{2}{|c|}{ متوسط الرتب } & \multirow[b]{2}{*}{ المتغيرات } \\
\hline & & مجموعة غير & مجموعة مميزة & مجموعة غير & مجموعة مميزة & \\
\hline$\cdots 1$ & r.A & 00 & 100 & 0.0. & 10.0. & الصدرية \\
\hline$\ldots 1$ & r.90 & 00 & 100 & 0.0. & 10.0. & المحاورة \\
\hline
\end{tabular}

يتضح من جدول (†) أن قيمة (Z) دالة عند مستوي ا ل.. ·بين متوسطات رتب درجات المجموعة المميزة

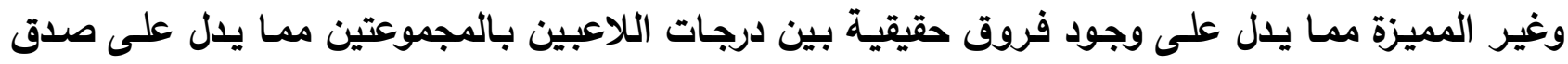

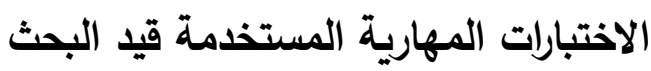

ثبات الاختبارات المهارية :

قام الباحث بحساب معامل الثبات بطريقة إعادة التطبيق للاختبارات المهارية المستخدمة بفاصل زمنى

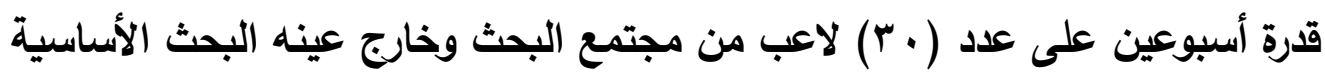
جدول (V)

يوضح ثبات الاختبارات المهارية ( ن=.+r )

\begin{tabular}{|c|c|c|}
\hline مستوى الدلالة & معامل الارتباط & الاختبـارات \\
\hline$\cdots 1$ & .94 & التمريرة الصدرية \\
\hline$\ldots 1$ & $.9 v$ & المحاورة \\
\hline
\end{tabular}

يتضح من جدول(V) أن معامل الارتباط بين التطبيق الأول والثاني للاختبارات المهاريـة قد تراوحت

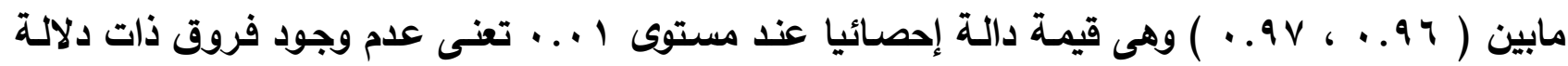
إحصائية بين التطبيق الأول والتطبيق الثاني مما يدل على ثبات الاختبارات المهارية. 


\section{- التجربة الاستطلاعية :}

قام الباحث بإجراء تجربة استطلاعية على عينة قوامها خمسة عشر لاعبا من المجتمع الأصلي

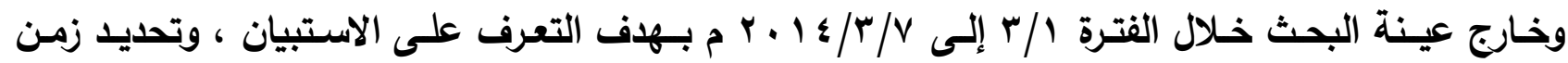
الإجابة عليه ، وتحديد الصعوبات التي يمكن أن تواجه التجربة الأساسية وأسفرت التجربة الاستطلاعية على الته التعرف على زمن الإجابة على الاستبيان ومناسبته للتطبيق . تطبيق استبيان الأكاءات المتعددة :

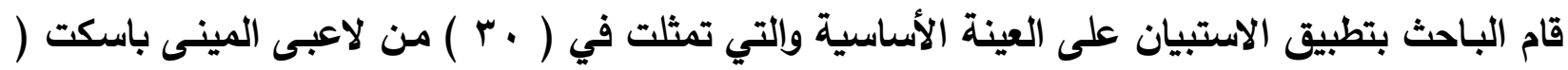

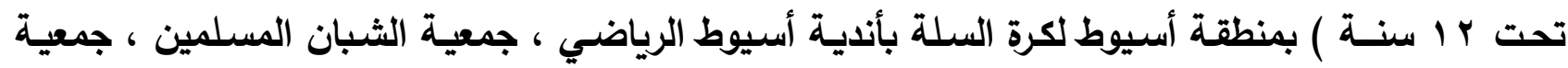

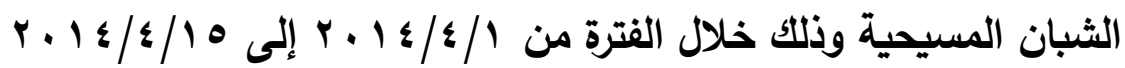
ع - جمع البيانات ومعالجتها إحصائياً :

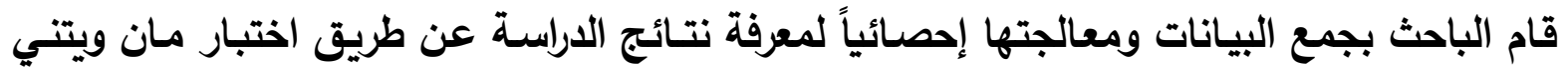

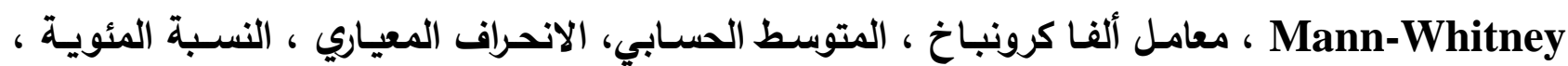
معامل الارتباط ، معادلات الانحدار المتعدد . معل

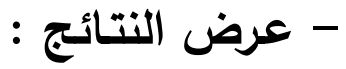

جدول (^)

درجات القطع والتكرارات والنسب المئوية المقابلة للاعبي الميني باسكت

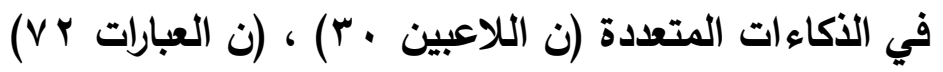

\begin{tabular}{|c|c|c|c|c|}
\hline \multirow[t]{2}{*}{ المستوى } & \multirow[t]{2}{*}{ النسبة المئوية } & \multirow[t]{2}{*}{ التكرارات } & \multirow[t]{2}{*}{ درجة القطع } & القيم الإحصائية \\
\hline & & & & المتغيرات \\
\hline القوي & $\% \leq$. & Ir & . . ' فأكثر & \multirow{3}{*}{ الأكاء المكاني } \\
\hline المتوسط & $\%$ \%. & 9 & $09-\leq 0$ & \\
\hline الضعيف & $\%$ \%. & 9 & ؟ ؛ فأقل & \\
\hline القوي & $\% \leq 7.77$ & $1 \varepsilon$ & ب ه فأكثر & \multirow{3}{*}{ الذكاء اللغوي } \\
\hline المتوسط & $\%$ \% & 7 & $01-r q$ & \\
\hline الضعيف & \%rr.rr & 1. & م ب فأقل & \\
\hline القوي & $\% \varepsilon$ & Ir & 7 ه فأكثر & \multirow{3}{*}{ الأكاء الاجتماعي } \\
\hline المتوسط & \%rr.ru & 1. & $00-\varepsilon Y$ & \\
\hline الضعيف & \%ч५.7 & $\Lambda$ & 1 1 فأقل & \\
\hline القوي & $\% \leq 7.77$ & $1 \varepsilon$ & . . ع فأكثر & \multirow{3}{*}{ الأكاء الثخصي } \\
\hline المتوسط & $\%$ r. & 9 & $r q-r$. & \\
\hline الضعيف & \%rr.rr & 1. & 9 Y فأقل & \\
\hline القوي & $\% \leq 7.77$ & $1 \varepsilon$ & . 1 فأكثر & \multirow[t]{3}{*}{ لذكاء الجسمي حركي } \\
\hline المتوسط & $\% 17.79$ & 0 & Vq-. & \\
\hline الضعيف & $\%$ & 11 & qه فأقل & \\
\hline
\end{tabular}


حيث تم حساب درجات القطع باستخدام المعادلة : درجة القطع = درجة الاستجابة × عدد عبارات المحور يتضح من جدول (^) أن هناك مستويات متباينة في الذكاءات الخمسـة للاعبي الميني باسكت بمحافظة أسيوط فمنهم الضعيف ، والمتوسط ، والقوي في مستوى الأكاءات قيد البحث.

جدول (9)

القيم الإحصائية للذكاءات المتعددة ومهارتي التمريرة الصدرية والمحاورة

$(r \cdot=\dot{0})$

\begin{tabular}{|c|c|c|c|c|c|}
\hline مستوى & معامل ارتباط & معامل ارتباط & الانحراف & المتوسط & القيم الإحصائية \\
\hline الالالة & المحاورة & التمريرة الصدرية & المعياري & الحسابي & المتغيرات \\
\hline$\cdots 1$ & . . &. .91 & $1 \ldots \varepsilon$ & $\leqslant 4.9$. & الأكاء المكاني \\
\hline$\cdots 1$ &..$\wedge \wedge$ & .9 . & $1 \ldots 0$ & $\leq \varepsilon$ & الأكاء اللغوي \\
\hline$\cdots 1$ & .99 & .9 & $1 . . v \leq$ & $\varepsilon r . \cdot r$ & الأكاء الاجتماعي \\
\hline$\cdots+1$ & .9 &..$\wedge 9$ & V.Ir & r.r. & الأكاء الشخصي \\
\hline$\cdots 1$ & $\cdots 9$. &..$\wedge 9$ & $10 . \wedge r$ & 91 & الذكاء الجسمي حركي \\
\hline
\end{tabular}

يتضح من جدول (9) وجود ارتباطات موجبة ودالة إحصائياً عند مستوى ا +.. بين الأنواع الخمسة للـكاءات : (المكاني، اللغوي، الاجتمـاعي، الشخصسي ، الجسـي حركي) وبين مهارتي التمريـرة الصـربة والمحاورة.

\section{(1.) جدول}

القيم الإحصائية بين التلاعبين المتميزين وغير المتميزين

من حيث المستوى المهاري في مستوى الأكاءات الخمسة (ن الكلية = . ب)

\begin{tabular}{|c|c|c|c|c|c|c|}
\hline \multirow[b]{2}{*}{ مستوى الدلالة } & \multirow[b]{2}{*}{ قيمة (Z) } & \multicolumn{2}{|c|}{ مجموع الرتب } & \multicolumn{2}{|c|}{ متوسط الرتب } & \multirow[b]{2}{*}{ المتغيرات } \\
\hline & & مجموعة غير & مجموعة مميزة & مجموعة غير & مجموعة مميزة & \\
\hline$\cdots 1$ & $\varepsilon .01$ & $\vee \wedge$ & $r \wedge v$ & 7.0. & r..0. & الذكاء المكاني \\
\hline$\ldots 1$ & $\varepsilon .01$ & $\vee \wedge$ & rAv & 7.0. & YI.0. & الأكاء اللغوي \\
\hline$\cdots 1$ & $\varepsilon .09$ & $\vee \wedge$ & $r \wedge v$ & 7.०. & r..0. & الاجتماعي \\
\hline$\cdots 1$ & $\varepsilon .09$ & $\vee \wedge$ & rAv & 7.0. & Y.o. & الثخصي \\
\hline$\cdots 1$ & $\varepsilon .0 \wedge$ & $\vee \wedge$ & rAv & 7.0. & r..0. & الأكاء الجسمي \\
\hline
\end{tabular}


يتضح من جدول ( • (1) وجود فروق دالة إحصائيا بين اللاعبين المتميزين (ن =^ 1) وغير المتميزين (ن= r l ) من حيث المستوي المهاري للتمريرة الصدرية والمحاورة في الذكاءات الخمسـة (المكاني ، اللغوي ، الاجتماعي ، الشخصي ، الجسمي حركي) لصالح اللاعبين المتميزين. جدول (11)

ملخص لنموذج الانحدار والتباين للذكاءات المتعددة كمتغيرات مستقلة والتمريرة الصدرية والمحاورة كمتغيرات تابعة

\begin{tabular}{|c|c|c|c|c|}
\hline \multirow[t]{2}{*}{ مستوى الدلالة } & \multirow[t]{2}{*}{ درجات الحرية } & \multirow[t]{2}{*}{ قيمة ف } & \multirow[t]{2}{*}{ قيمة رب } & القيم الإحصائية \\
\hline & & & & المتغيرات \\
\hline$\cdots \cdot 1$ & 0 & ro.rs &..$\wedge 0$ & التمريرة الصدرية \\
\hline$\ldots 1$ & 0 & 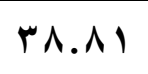 &..$\wedge 7$ & المحاورة \\
\hline
\end{tabular}

يتضح من جدول (1 (1) أن قيم "ف" دالة إحصائياً عند مستوى I +... في نموذج الانحدار، مما يعني وجود قدرة تتبؤية للأكاءات الخمسة مجتمعة بكل من المتفيرين التابعين التمريرة الصدرية والمحاورة. - مناقشة النتائج وتفسيرها : من خلال البيانات والمعالجات الإحصائية وفي ضوء هدف البحث يتضح من جدول (^) وجود مستويات متباينة في الاككاءات المتعددة الخمسة (المكاني ، اللغوى ، الاجتماعي ، الثخصي ، الجسمي حركي) لاى لاعبي

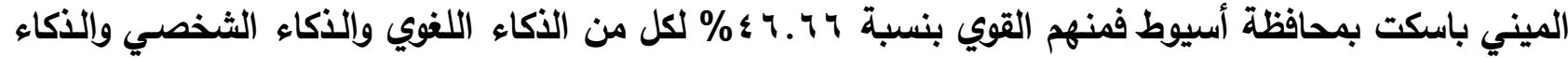

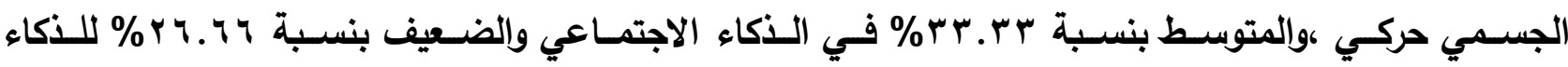
الاجتمـاعي وفقا لارجـة استجابة الكلاعبين لعبارات الاستبيان وهذا يحقق الفرض الأول وهو توجــ مستويــات متباينة لأنواع الأكاءات المتعددة قيد البحث لاى لاعبي المينى باسكت بمحافظة أسيوط . هذا يتفق وما أشار إليه جاردنر في نظريـة الذكاءات المتعددة ب9 19 (Y (Y) بوجود مستويات متفاوتة لكل نوع من أنواع الأكاءات المتعددة لاى الفرد الواحد وكذلك بين الأفراد وبعضهم البعض. وهنـا يثـير الباحث إلى ضـرورة أن يسـتخدم مـدبي كـرة السـلة اسـتراتيجيات متنوعـة خـلال تعليمهم الناشئين وبخاصة لاعبي الميني باسكت بحيث يتم مراعاة الفروق الفردية بين اللاعبين طبقا لقدراتهم المختلفة حيث أنهم يتعلمون وفقا لما لايهم من قدرات وذكاء ات. كما يتضح من جدول (9) وجود ارتباطات موجبة ودالة إحصائياً عند مستوى ا ـ... بين الأنواع الخمسة للاذكاءات : (المكاني، اللغوي، الاجتماعي، الثخصي ، الجسمي حركي) وبين مهارتي التمريرة الصدرية ، ومهارة

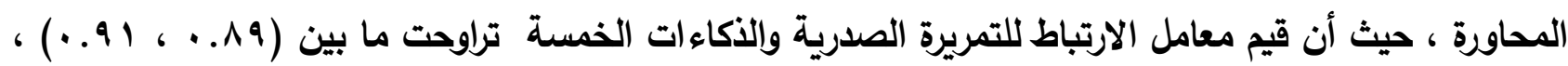

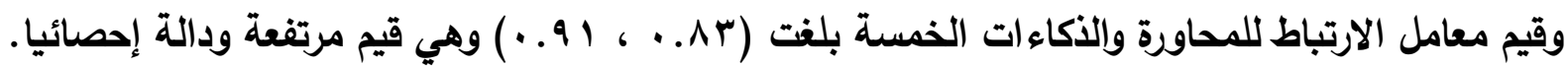
وهذا يحقق الفرض الثاني وهـو توجد علاقة إرتباطية موجبة دالـة إحصـائياً بـين أنـواع الذكاءات المتعددة قيد البحث ومهارتي التمريرة الصدرية والمحاورة للاعبى المينى باسكت بمحافظة أسيوط. 
كما يتفق هذا مـع ما أشسارت إليه دراسـة كيرستون وكينيدي 1999 Christison \& Kenedy

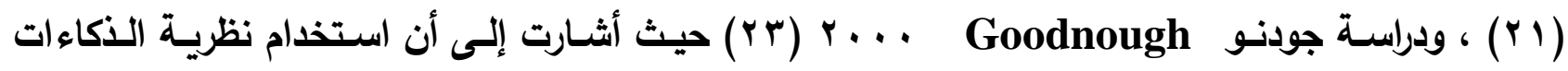
المتعددة كمدخل تعليمي يعمل على تنمية مستوى الذكاءات المتعددة لاى المتعلمين يؤدى إلى تحقيق نتائج تعليمية أفضل.

يتضح من جدول ( • 1) وجود فروق دالة إحصائيا بين اللاعبين المتميزين وغير المتميزين من حيث المباء

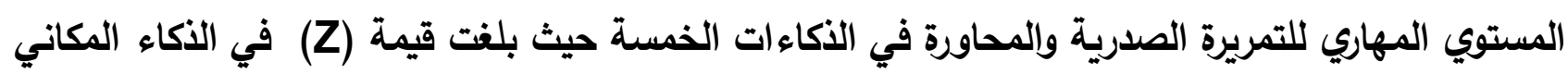

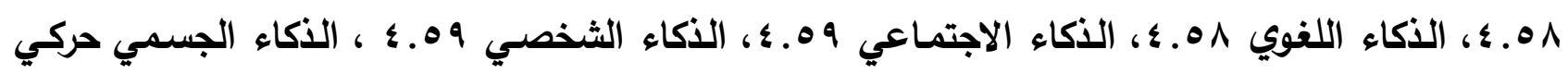

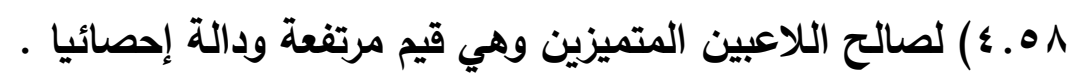

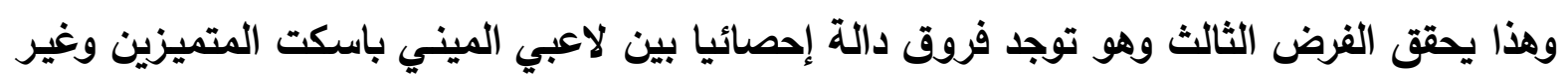
المتميزين من حيث المستوى المهاري لمهارتي التمريرة الصدرية والمحاورة في مستوى الاكاءات المتعددة قيد

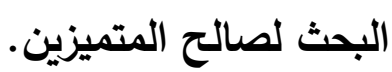

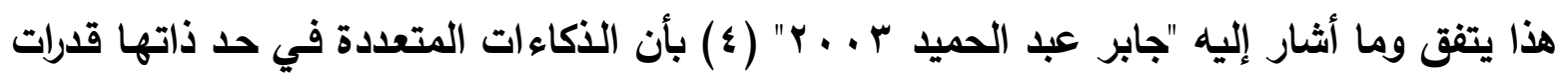

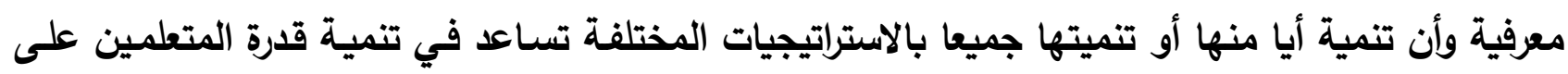

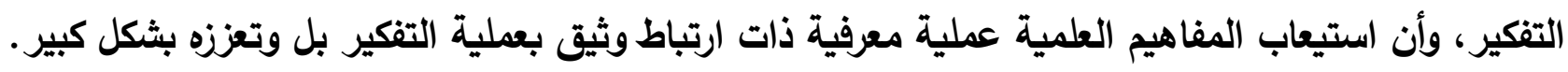

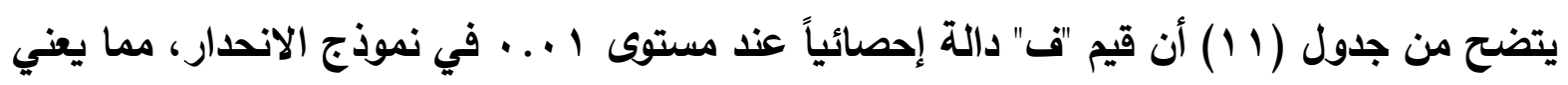

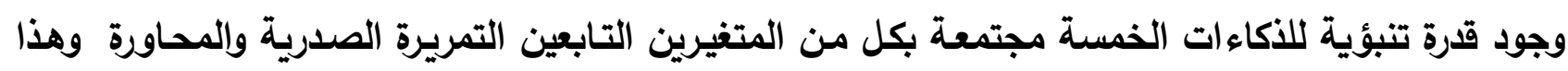

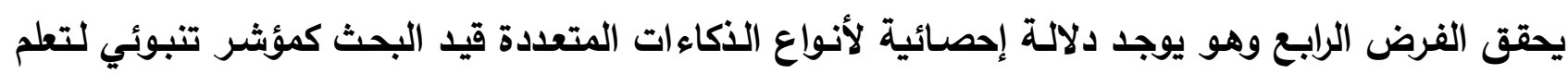
مهارتى التمريرة الصدرية والمحاورة للاعبى المينى باسكت بمحافظة أسيوط.

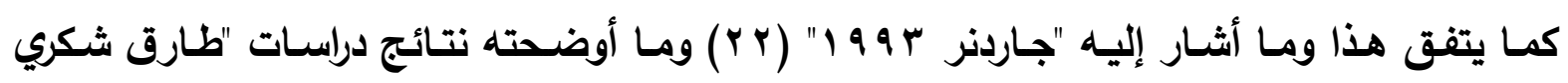

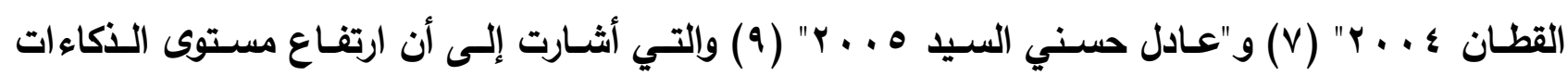

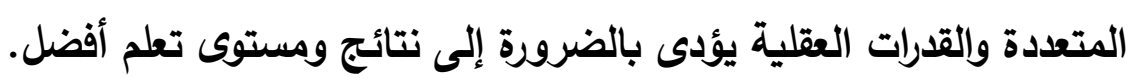
- الإستخلاصسات : من خلال الإطار المرجعي للباحث وفي ضوء النتائج التي تم الوصول إليها تم استخلاص ما يلي :

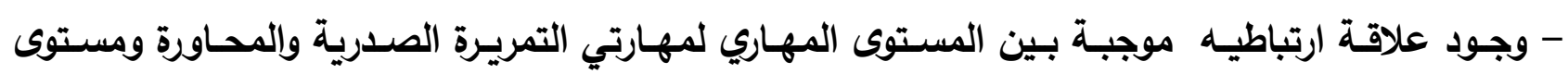
الأكاءات المتعدة لاى لاعبي الميني باسكت بمحافظة أسيوط. 
1- يوصي الباحث باستخدام نظرية جاردنر للذكاءات المتعددة في تعليم مهارات الألعاب الرياضية الجماعية والفردية.

r- إجراء دراسات مماثلة على مراحل سنية مختلفة في لعبة كرة السلة .

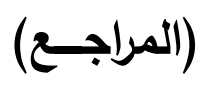

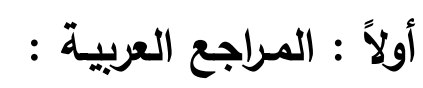

1- أبو بكر محمد محم مرسي : " أثر استخدام أسلوب تحليل المهمة في تعليم بعض مهارات كرة السلة

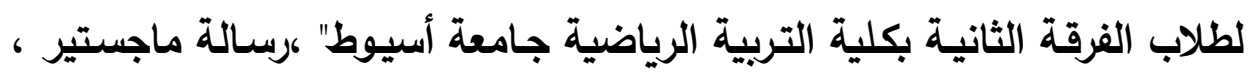
كلية التربية الرياضية ،جامعة أسيوط r . . rم.

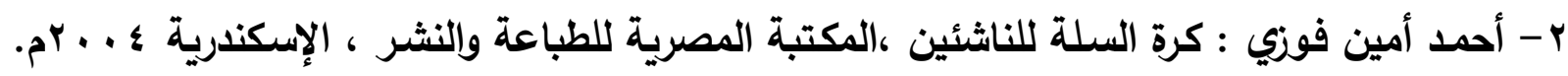
r- إمام مصطفى سيد : فاعلية تقييم الأداء باستخدام أنثطة الذكاءات المتعددة لجاردنر في اكتثـاف الموهوبين من تلاميذ المرحلة الابتدائية ، مجلة كلية التربية ، جامعة أسيوط

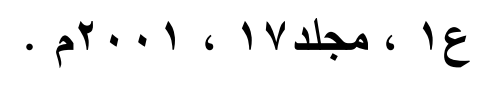

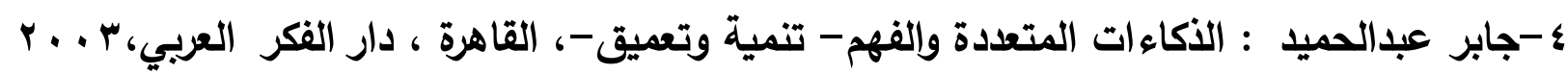
ه- حسين محمد عبد الهادي : قياس وتقييم الذكاءات المتعددة ، عمان ،دار الفكر ، ب. . ץ. צ-خطابية ، عبدالله والبدور ، عدنان : أثر استخدام إستراتيجيات الذكاءات المتعددة في تدريس العلوم في التحصيل وإكتساب مهارات العلم لدي تلاميذ الصف السابع الأساسي

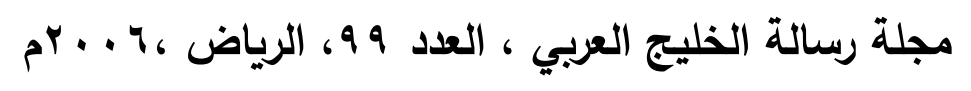

- طارق شكرى القطان : تأثير برنامج تدريب عقلى على تنمية مهارة التصويبة الثلاثية فى كرة السلة ، مجلة أسيوط لعلوم وفنون التربية الرياضية ، عدد 1 ، جزء ب ،

$$
\text { نوفمبر \& }
$$


^- عادل حسني السيد ، وليد إبراهيم أحمد: أثر استخدام أسلوب التدريب علي تعلم بعض المهارات الدفاعية لكرة السلة ، مجلة أسيوط لعلوم وفنون التربية الرياضية ، كلية

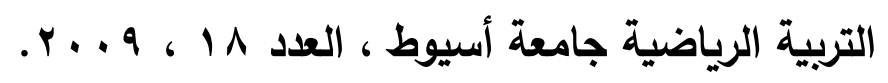

9- عادل حسني السيد : برنامج تعليمي مقترح لتنمية الإدراك الحس حركي وأثرة على تعلم مهارات التصويب فى كرة السلة ، مجلة أسيوط لعلوم وفنون التربية الرياضية ، العدد

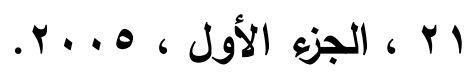

• 1 - عبد العزيز النمر ، مدحت صالح سـيد : " كرة السـلة تعليم وتدريب " دار القلم والنشر ، القـاهرة $.0199 \mathrm{~V}$

1 ا- عبيد وليم : الضرب في ^ وأثره علي المنظومة المعرفية للمنهج ، المؤتمر العلمي الساد عشر ، مناهج التعليم والثورة المعرفية التكنولوجية المعاصرة ، الجمعية المصرية للمناهج وطرق التدريس ، مجلد ا جامعة عين شمس ، 1. . Y. r ا- غنيم حمح عبد السلام : مفاهيم أساسية في علم النفس المعرفي ، القاهرة ، دار الفكر العربي .$r \ldots$

r ا - فوزي طه ، ورجب أحمد الكلزة : المناهج المعاصرة ، القاهرة ، مطابع الفن ، به19 1.

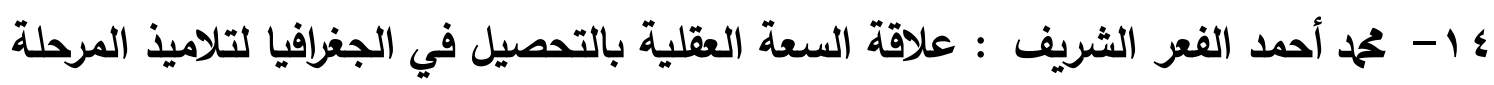
المتوسطة ، رسالة الخليج العربي ، الرياض ، ع؛ ؛ ، السنة بـ 1 ، ب 99 ام ه 1 - محمد عبد الرحيم إسماعيل : الأساسيات المهارية وإلخطية الهجومية في كرة السلة ، منثأة

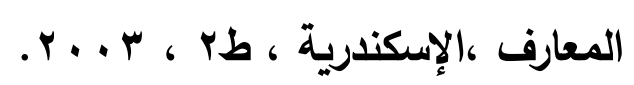

19

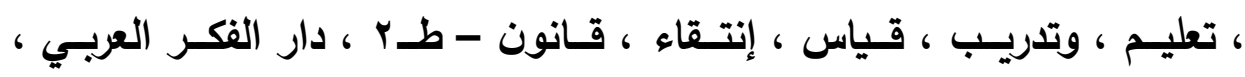


IV - محمة محمود عبد الدايـم ، محمـد صبحي حسانين : القيـاس في كرة السـلة ، دار الفكر العربي ، القاهرة ع ع 9 (ام.

$$
\begin{aligned}
& 1 \text { 1 - مدحت صالح سيد : الاتجاهات الحديثة في إعداد مدرب كرة السلة ، مقال علمي ، } 999 \text { ام. } \\
& 9 \text { 1 - هدي بنت محم بابطين : فاعلية إستراتيجيات الذكاءات المتعددة في تدريس العلوم علي تنمية } \\
& \text { الاستيعاب المفاهيم والتفكير العلمي والدافع للانجاز لاي تلميذات الصف } \\
& \text { الثالث متوسط بمدينة مكة المكرمة ، المؤتمر العلمي الحادي والعشرون ، } \\
& \text { دار الضيافة ، جامعة عين شمس ، المجلد الرابع ، 9 . . ؟ . }
\end{aligned}
$$$$
\text { ثانيا : المراجع الأجنبية : n }
$$

20- Burman , T . \& Evans , D. ( 2003) .improving reading skills through multiple intelligences and parental involvement . http://search.epnet. Com /logic . aspx? direct = true \& $\mathrm{db}=$ Eric \& an = ED478515 .

21-Christi son M\& Kennedy, M.(1999) Multiple Intelligences Theory and Practice In Adult Esl . Ed 441350. Eric Digest From Word Wide Web .Http:// www.ED. Gov/ Data based / Eric Digsled 44/350 html.

22- Gardener .H. (1993) : Multiple intelligences: theory in Practice . New York, Basic Books

23-Goodnough, K (2000) : Exploring Multiple Intelligence Theory In Context of Science Approach, Philadelphia , Pa : Open University Press.

24- Hearne, D.stone ,s ( 1995 ) .Multiple intelligences and underachievement : Lessons from individuals with learning disabilities journal of learning Disabilities , 28,7

25- Hodson,D ( 1998 ) teaching and learning Science : tward, personalized approach. Phialadelph, PA:open- university press 
26- Hubbard , T. \& Newell , M .(1999) . improving academic achievement in reading and writing in primary grades . http://search . epent . com $/ \operatorname{login}$. aspx $?$ direct $=$ true $\& \mathrm{db}=\operatorname{eric} \&$ an $=\mathbf{E D 4 3 8 5 1 8}$.

27- Martin, D David j.(2000) : Elementary Science Methods A constructivist Approach, wads worth Belmont, Second Edition ,USA.

28- Snyder, R. (2000) ).The relationship between Learning styles multiple Intelligences and academic achievement of hig school student High school Journal, 83 , 2 ( PP11-12 ) 